\title{
Interstitial Atom Engineering in Magnetic Materials
}

\author{
Jiro Kitagawa ${ }^{1, * \mathbb{C}}$, Kohei Sakaguchi ${ }^{1}$, Tomohiro Hara ${ }^{1}$, Fumiaki Hirano ${ }^{1}$, Naoki Shirakawa ${ }^{2}$ \\ and Masami Tsubota ${ }^{3}$ D \\ 1 Department of Electrical Engineering, Faculty of Engineering, Fukuoka Institute of Technology, \\ 3-30-1 Wajiro-higashi, Higashi-ku, Fukuoka 811-0295, Japan; s1451020@bene.fit.ac.jp (K.S.); \\ s1552037@bene.fit.ac.jp (T.H.); s1652044@bene.fit.ac.jp (F.H.) \\ 2 Flexible Electronics Research Center, National Institute of Advanced Industrial Science and Technology, \\ Tsukuba, Ibaraki 305-8565, Japan; shirakawa.n@aist.go.jp \\ 3 Physonit Inc., 6-10 Minami-Horikawa, Kaita Aki, Hiroshima 736-0044, Japan; tsubota@physonit.jp \\ * Correspondence: j-kitagawa@fit.ac.jp; Tel.: +81-(0)92-606-4579
}

Received: 17 November 2020; Accepted: 3 December 2020; Published: 6 December 2020

\begin{abstract}
Interstitial light elements play an important role in magnetic materials by improving the magnetic properties through changes of the unit cell volume or through orbital hybridization between the magnetic and interstitial atoms. In this review focusing on the effects of interstitial atoms in Mn-based compounds, which are not well researched, the studies of interstitial atoms in three kinds of magnetic materials (rare-earth $\mathrm{Fe}-$, $\mathrm{Mn}$-, and rare-earth-based compounds) are surveyed. The prominent features of Mn-based compounds are interstitial-atom-induced changes or additional formation of magnetism - either a change from antiferromagnetism (paramagnetism) to ferromagnetism or an additional formation of ferromagnetism. It is noted that in some cases, ferromagnetic coupling can be abruptly caused by a small number of interstitial atoms, which has been overlooked in previous research on rare-earth Fe-based compounds. We also present candidates of Mn compounds, which enable changes of the magnetic state. The Mn-based compounds are particularly important for the easy fabrication of highly functional magnetic devices, as they allow on-demand control of magnetism without causing a large lattice mismatch, among other advantages.
\end{abstract}

Keywords: interstitial atom; Mn-based compounds; rare-earth Fe-based compounds; rare-earth-based compound; Bethe-Slater curve; ferromagnetic; antiferromagnetic; permanent magnet

\section{Introduction}

Some crystal structures possess interstitial crystallographic sites, which light elements such as hydrogen, boron, carbon, nitrogen, and oxygen atoms can occupy. There is a rather long history of metallurgical, physical, and chemical research studies on interstitial atoms [1,2]. In past years, domain control of ferromagnets has been studied [1]. Since the 1980s, interstitial atoms have attracted intense attention related to the improvement of magnetic properties of rare-earth Fe and Co-based permanent magnets [2-6].

Interstitial atoms have two major roles-influencing the stability of the crystal structure and in the modification or change in magnetic properties. In the former case, small amounts of interstitial light elements are required to stabilize the desired crystal structure; compounds without interstitial atoms would not exist in thermal equilibrium. In the latter case, interstitial atoms affect the crystal structure parameters, such as the interatomic distances between magnetic atoms or the orbital hybridization between magnetic and interstitial atoms, consequently meaning the magnetic ordering temperature, the magnetic moment, the magnetic structure, and other factors can be altered.

The most well-studied platforms for interstitial atoms are rare-earth Fe-based permanent magnets. The improvements of the magnetic properties have mainly been achieved through the addition of light 
elements such as boron, carbon, and nitrogen atoms. The Bethe-Slater curve is one of the criteria needed to understand whether metal $3 d$ transition elements of $\mathrm{Cr}, \mathrm{Mn}, \mathrm{Fe}, \mathrm{Co}$, and $\mathrm{Ni}$ possess ferromagnetic (FM) or antiferromagnetic (AFM) states (see Figure 1) [7-10]. This curve exhibits the exchange coupling as a function of the interatomic distance. Fe falls in the FM region near to the border between FM and AFM states. Therefore, in Fe-based compounds, a shorter Fe-Fe distance (shrinkage of the unit cell volume) favors an AFM state, while a longer Fe-Fe distance (an expansion of the unit cell volume) favors the FM state [11-13]. With increasing Fe-Fe distance, smaller overlapping of $3 d$ wave functions makes the $3 d$ band narrower, which leads to the FM state, and in most cases the Curie temperature $T_{C}$ is enhanced.

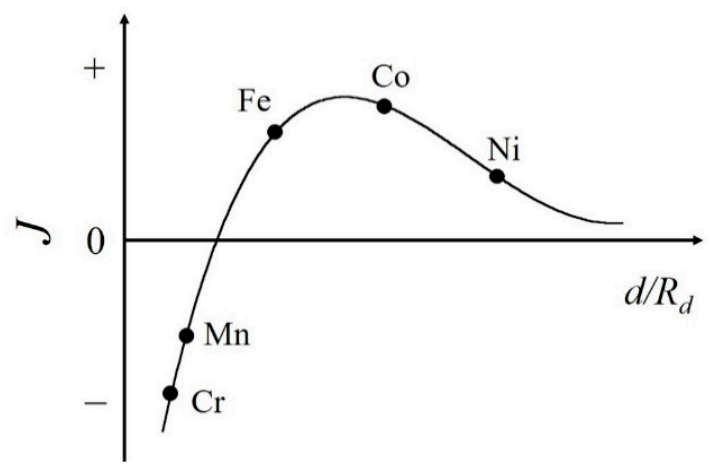

Figure 1. Schematic view of the Bethe-Slater curve. Here, $J, d$, and $R_{d}$ represent the magnetic exchange coupling between atoms, the interatomic distance, and the radius of the $3 d$ shell, respectively.

On the other hand, the effects of interstitial atoms in Mn-based compounds are not well researched. As shown in Figure 1, the Mn atom itself shows the AFM ground state, however the expanded Mn-Mn distance in Mn-based compounds leads to the FM state. Mn compounds are indispensable for both FM and AFM materials. For example, MnBi and MnAl have attracted much attention as permanent magnets [14-18]. MnSi has been extensively studied as a magnetic material with a skyrmion state, which is a noncollinear magnetic structure. The skyrmion domains can be driven by the low current density threshold [19]. Recently, $\mathrm{Mn}_{3} \mathrm{Sn}$ has been intensively studied as a topological antiferromagnet [20] and is a candidate next-generation spintronics material. If the effects of interstitial atoms are well understood, they can be highly useful in the development of spintronics devices or highly functional magnetic devices, which can be developed via easy on-demand control of the magnetic state.

In this review, we present information on the effects of interstitial atoms in rare-earth Fe-, Mn-, and rare-earth-based compounds, especially focusing on Mn-based compounds. We introduce the frequently studied Mn-based compounds, showing the changes of magnetic states caused by the interstitial atoms, as well as our recent results. Interestingly, a change in the magnetic ground state or an additional formation of the FM state caused by interstitial atoms is possible. Specifically, our results highlight an abrupt emergence of FM exchange coupling above room temperature caused by the addition of a small amount of light elements, which has not been clearly reported for rare-earth Fe-based compounds. Additionally, candidate crystal structures for Mn compounds are presented, in which a magnetic state can be changed using interstitial atoms. Finally, perspectives concerning the development of magnetic devices based on Mn-based compounds and the strategy for further improvement of magnetic properties are outlined.

\section{Rare-Earth Fe-Based Compounds}

\section{1. $T h_{2} \mathrm{Zn}_{17}$-Type}

$\mathrm{R}_{2} \mathrm{Fe}_{17} \mathrm{~N}_{\mathrm{x}}\left(\mathrm{R}=\right.$ light rare-earth) represents the permanent magnets with the hexagonal $\mathrm{Th}_{2} \mathrm{Zn}_{17}$-type structure (space group: $R \overline{3} m$, No. 166). There is an interstitial Wyckoff position $9 e$ for nitrogen 
atoms. The roles of nitrogen atoms are the enhancement of $T_{\mathrm{C}}$ and the saturated magnetization $M_{\mathrm{S}}$ and the change in magnetic anisotropy. For example, $T_{\mathrm{C}}=389 \mathrm{~K}$ and $M_{\mathrm{S}}=1.00 \mathrm{~T}$ at a room temperature of $\mathrm{Sm}_{2} \mathrm{Fe}_{17}$ are increased to $749 \mathrm{~K}$ and $1.54 \mathrm{~T}$, respectively, in $\mathrm{Sm}_{2} \mathrm{Fe}_{17} \mathrm{~N}_{3}$ (see Table 1). Moreover, the in-plane anisotropy in $\mathrm{Sm}_{2} \mathrm{Fe}_{17}$ is changed to uniaxial anisotropy by the nitriding, which is advantageous for application as permanent magnets.

Table 1. The magnetic and structural properties of rare-earth Fe-based compounds with and without interstitial atoms, where $a$ and $c$ are the lattice parameters, and $V$ is the unit cell volume. RT means the room temperature. Data are from the references listed in the table.

\begin{tabular}{cccccccc}
\hline Compound & $\boldsymbol{T}_{\mathbf{C}}(\mathbf{K})$ & $\boldsymbol{M}_{\mathbf{S}} @ \mathbf{R T}(\mathbf{T})$ & $\begin{array}{c}\text { Easy Magnetization } \\
\text { Direction }\end{array}$ & $\boldsymbol{a}(\mathbf{\mathrm { A }})$ & $\boldsymbol{c}(\AA)$ & $\boldsymbol{V}\left(\AA^{3}\right)$ & $\boldsymbol{R e f .}$ \\
\hline $\mathrm{Sm}_{2} \mathrm{Fe}_{17}$ & 389 & 1.00 & in-plane & 8.55 & 12.45 & 788.2 & {$[21,22]$} \\
$\mathrm{Sm}_{2} \mathrm{Fe}_{17} \mathrm{~N}_{3}$ & 749 & 1.54 & c axis & 8.74 & 12.70 & 840.2 & {$[23,24]$} \\
$\mathrm{Sm}_{2} \mathrm{Fe}_{17} \mathrm{C}_{3}$ & 668 & 1.43 & c axis & 8.744 & 12.572 & 832.4 & {$[25,26]$} \\
$\mathrm{SmFe}_{11} \mathrm{Ti}$ & 584 & 1.15 & c axis & 8.56 & 4.80 & 351.7 & {$[27,28]$} \\
$\mathrm{SmFe}_{11} \mathrm{TiN}$ & 769 & 1.28 & in-plane & 8.64 & 4.84 & 361.3 & {$[28,29]$} \\
$\mathrm{NdFe}_{11} \mathrm{Ti}$ & 547 & 1.38 & in-plane & 8.585 & 4.789 & 353.0 & {$[30,31]$} \\
$\mathrm{NdFe}_{11} \mathrm{TiN}$ & 729 & 1.48 & c axis & 8.701 & 4.844 & 366.7 & {$[32,33]$} \\
$\mathrm{SmFe}_{9} \mathrm{Si}_{2} \mathrm{C}_{1.0}$ & 462 & 0.88 & c axis & 10.057 & 6.512 & 658.7 & {$[34]$} \\
$\mathrm{SmFe}_{9} \mathrm{Si}_{2} \mathrm{C}_{1.5}$ & 492 & 0.90 & c axis & 10.082 & 6.554 & 666.1 & {$[34]$} \\
\hline
\end{tabular}

The addition of nitrogen atoms expands the lattice parameters $a$ and $c$, resulting in the increased $\mathrm{Fe}-\mathrm{Fe}$ interatomic distance and the enhancement of $T_{\mathrm{C}}$. Actually, in $\mathrm{Sm}_{2} \mathrm{Fe}_{17} \mathrm{~N}_{3}, T_{\mathrm{C}}$ is almost doubled, which is much larger than that in the case of $\mathrm{ThMn}_{12}$-type compounds (see also Section 2.2 and Table 1). The difference is well correlated with the rate of unit-cell-volume change $\Delta V / V$ by the interstitial atoms, which is defined by

$$
\frac{\Delta V}{V}=\frac{V_{\mathrm{w}}-V_{w / 0}}{V_{\mathrm{w} / \mathrm{o}}} \times 100
$$

where $V_{\mathrm{w} / \mathrm{o}}$ and $V_{\mathrm{w}}$ are the unit cell volumes without and with interstitial atoms, respectively. We note here that the compound without interstitial atoms is hereafter often called the parent compound. For example, $\Delta V / V=6.6 \%$ in $\mathrm{Sm}_{2} \mathrm{Fe}_{17} \mathrm{~N}_{3}$ is larger than that in $\mathrm{ThMn}_{12}$-type $\mathrm{SmFe}_{11} \mathrm{TiN}(2.7 \%)$. The larger $\Delta V / V$ for $\mathrm{Sm}_{2} \mathrm{Fe}_{17} \mathrm{~N}_{3}$ is ascribed to the fact that Fe magnetic moments in the $\mathrm{Th}_{2} \mathrm{Zn}_{17}$-type structure are less itinerant.

\section{2. $T h M n_{12}$-Type}

The well studied system is $\mathrm{RFe}_{11} \mathrm{Ti}$ (R: rare-earth) series (I4/mmm, No. 139). This structure allows the interstitial nitrogen atoms to occupy the $2 b$ site. In $\mathrm{SmFe}_{11} \mathrm{TiN}$ or $\mathrm{NdFe}_{11} \mathrm{TiN}$, the nitrogen addition enhances $T_{C}$ by about $30 \%$, which is smaller than that of the $\mathrm{Th}_{2} \mathrm{Zn}_{17}$-type system (see Table 1 ). As mentioned above this is due to the smaller $\Delta V / V$ under the addition of nitrogen $\left(2.7 \%\right.$ for $\mathrm{SmFe}_{11} \mathrm{TiN}$ and $3.9 \%$ for $\mathrm{NdFe}_{11} \mathrm{TiN}$ ). The magnetic anisotropy of $\mathrm{RFe}_{11} \mathrm{Ti}$ is determined primarily due to the single-ion contribution of $\mathrm{R}$ ion, thus $\mathrm{NdFe}_{11} \mathrm{Ti}$ and $\mathrm{SmFe}_{11} \mathrm{Ti}$ show the planar and $c$ axis anisotropies, respectively. In each compound, the sign of magnetic anisotropy constant $K_{1}$ is reversed by the nitrogen addition and a good candidate of the permanent magnet is consequently $\mathrm{NdFe}_{11} \mathrm{TiN}$.

The first-principle studies have revealed that $\mathrm{NdFe}_{12} \mathrm{~N}$, which possesses an Fe concentration higher than that of $\mathrm{NdFe}_{11} \mathrm{TiN}$ and is more favorable for a permanent magnet, has excellent magnetic properties [35-37], however, it is thermodynamically unstable in bulk form. The thin film fabrication allows the growth of $\mathrm{NdFe}_{12} \mathrm{~N}_{\mathrm{x}}$, which shows a superior $M_{\mathrm{S}}=1.7 \mathrm{~T}$ compared to $\mathrm{Nd}-\mathrm{Fe}-\mathrm{B}$ magnets [38]. The coercivity of $\mathrm{NdFe}_{12} \mathrm{~N}_{\mathrm{x}}$ is rather low, however, a born doped $\mathrm{Sm}\left(\mathrm{Fe}_{0.8} \mathrm{Co}_{0.2}\right)_{12}$ is recently reported to be a highly coercive material with $1.2 \mathrm{~T}$ [39]. The microstructure of the compound exhibits columnar-shaped $\mathrm{Sm}\left(\mathrm{Fe}_{0.8} \mathrm{Co}_{0.2}\right)_{12}$ grains, surrounded by a born-rich amorphous phase. The domain wall pinning at the grain boundary is responsible for the high coercivity [39]. 
Mao et al. reported a $B H$ energy product of $\mathrm{ThMn}_{12}$-type compound [40]. They have investigated the magnetic properties of powdered $\operatorname{PrFe}_{12-\mathrm{x}} \mathrm{V}_{\mathrm{x}}$ and the nitride compound. $\operatorname{Pr}(\mathrm{Fe}, \mathrm{V}){ }_{12} \mathrm{~N}_{1.6}$ exhibits the maximum $\mathrm{BH}$ energy product of $135 \mathrm{~kJ} / \mathrm{m}^{3}$.

\section{3. $B a C d_{11}$-Type}

The tetragonal $\mathrm{BaCd}_{11}$-type structure represented by $\mathrm{RFe}_{9} \mathrm{Si}_{2} \mathrm{C}_{\mathrm{x}}$ (Table 1 ) is a candidate for a next-generation rare-earth Fe-based permanent magnet. It is interesting that the addition of carbon atoms is required to stabilize the $\mathrm{BaCd}_{11}$-type structure. In $\mathrm{RFe}_{9} \mathrm{Si}_{2} \mathrm{C}_{\mathrm{x}}$, the carbon atom occupies the interstitial $8 \mathrm{c}$ site of the tetragonal space group of $I 4_{1} /$ amd (No. 141). $T_{\mathrm{C}}$ progressively increases with the increase of $x$, for example, $T_{C}=367 \mathrm{~K}_{\text {of }} \mathrm{SmFe}_{9} \mathrm{Si}_{2} \mathrm{C}_{0.5}$ is enhanced to $492 \mathrm{~K}$ in $\mathrm{SmFe}_{9} \mathrm{Si}_{2} \mathrm{C}_{1.5}$, accompanying the volume expansion [30]. The magnetic anisotropy depends on the $\mathrm{R}$ atom; in-plane anisotropy is observed in $\mathrm{R}=\mathrm{Ce}$ or $\mathrm{Nd}$, whilst on the other hand, $\mathrm{R}=\mathrm{Sm}$ possesses the $c$ axis anisotropy.

\subsection{Remark on Hybridization Effect}

Through the extensive studies of rare-earth Fe-based permanent magnets, it is revealed that stronger orbital hybridization in the covalent bond between Fe and an interstitial atom tends to reduce the magnetic moment. The strength of the covalent bond is well reflected by $\Delta V / V$ under the addition of light elements; $\Delta V / V$ is not so large when the hybridization is stronger. $\Delta V / V$ is generally larger for the nitrogen addition compared to the carbon one (see, for example, $S_{2} \mathrm{Fe}_{17} \mathrm{~N}_{3}$ and $\mathrm{Sm}_{2} \mathrm{Fe}_{17} \mathrm{C}_{3}$ in Table 1).

\section{Mn-Based Compounds}

In this section, we gathered as many Mn-based room temperature ferromagnets as possible.

\subsection{Hydrogen-Absorbed ( $R$ or $T h)_{6} \mathrm{Mn}_{23}$}

$\mathrm{R}_{6} \mathrm{Mn}_{23}\left(\mathrm{R}=\right.$ rare earth) series and $\mathrm{Th}_{6} \mathrm{Mn}_{23}$ crystallize into the cubic $\mathrm{Th}_{6} \mathrm{Mn}_{23}$-type structure with the space group $F m \overline{3} m$ (No. 225). R atoms occupy the $24 e$ site, and Mn atoms the $4 b$, the $24 d$ and the two $32 f$ sites. All $\mathrm{R}_{6} \mathrm{Mn}_{23}$ compounds show FM orderings at a $T_{\mathrm{C}}$ higher than $300 \mathrm{~K}$, which are induced by $\mathrm{Mn}$ magnetic moments. On the other hand, $\mathrm{Th}_{6} \mathrm{Mn}_{23}$ remains a paramagnet down to low temperatures. The hydrogen absorption generally expands the unit cell volume (see Figure 2 and Table 4), whereas the occupation site of the hydrogen atom is not clear. Although the $T_{C}$ of non-hydrogenated $\mathrm{R}_{6} \mathrm{Mn}_{23}$ rises with increasing volume, most of the hydrogen-absorbed compound shows the suppressed $T_{C}$ compared to each parent compound. For example [41], $T_{C}=461 \mathrm{~K}$ of $\mathrm{Gd}_{6} \mathrm{Mn}_{23}$ is reduced to $T_{\mathrm{C}}=2.66 \mathrm{~K}$ in $\mathrm{Gd}_{6} \mathrm{Mn}_{23} \mathrm{H}_{\mathrm{x}}$. The saturated moment is also highly reduced (49 $\mu_{\mathrm{B}} /$ f.u. to $14.2 \mu_{\mathrm{B}} /$ f.u.) [41]. The opposite behavior is confirmed for $\mathrm{Th}_{6} \mathrm{Mn}_{23}$, in spite of the similar volume change by the hydrogenation. The hydrogenated $\mathrm{Th}_{6} \mathrm{Mn}_{23}$ shows an emergence of ferromagnetism with $T_{C}=335 \mathrm{~K}$, although the saturated moment of $\mathrm{Mn}$ is not so high $\left(16.5 \mu_{\mathrm{B}} / \mathrm{f} . \mathrm{u}\right.$.) [41]. Considering that $\mathrm{R}$ and Th ions are in the trivalent and the tetravalent state, respectively, the exchange coupling between Mn magnetic moments would significantly depend on the valence electron count per atom (VEC). We note that $\mathrm{Th}_{6} \mathrm{Mn}_{23}$ is the typical Mn-based compound showing the change in magnetic state by interstitial atoms. The saturated moment induced in the FM state of the hydrogenated compound is rather low, indicating a strong orbital hybridization between Mn and hydrogen atoms and/or a complex magnetic structure.

\subsection{Hydrogen-Absorbed $Y M n_{2}$}

The crystal structure of $\mathrm{YMn}_{2}$ is the cubic $\mathrm{MgCu}_{2}$-type structure with the space group of $F d \overline{3} \mathrm{~m}$ (No. 227). Y and Mn atoms occupy the $8 a$ and the $16 d$ site, respectively. $\mathrm{YMn}_{2}$ can absorb hydrogen atoms as in $\mathrm{R}_{6} \mathrm{Mn}_{23}$. Although $\mathrm{YMn}_{2}$ is paramagnetic down to low temperatures, $\mathrm{YMn}_{2} \mathrm{H}_{\mathrm{x}}$ shows a lattice expansion under hydrogenation, which induces a ferromagnetism with $T_{\mathrm{C}}=284 \mathrm{~K}$ and a 
saturation moment of $0.52 \mu_{\mathrm{B}} / \mathrm{f}$.u. [41]. There are many $\mathrm{RMn}_{2}$ compounds with the same structure, however, we do not make the magnetic ordering temperature vs. unit cell volume plot, because the accurate nature of the magnetic order is still unknown for each compound [42]. $\mathrm{YMn}_{2}$ can also be regarded as the compound, realizing the change from paramagnetism to ferromagnetism by interstitial atoms.

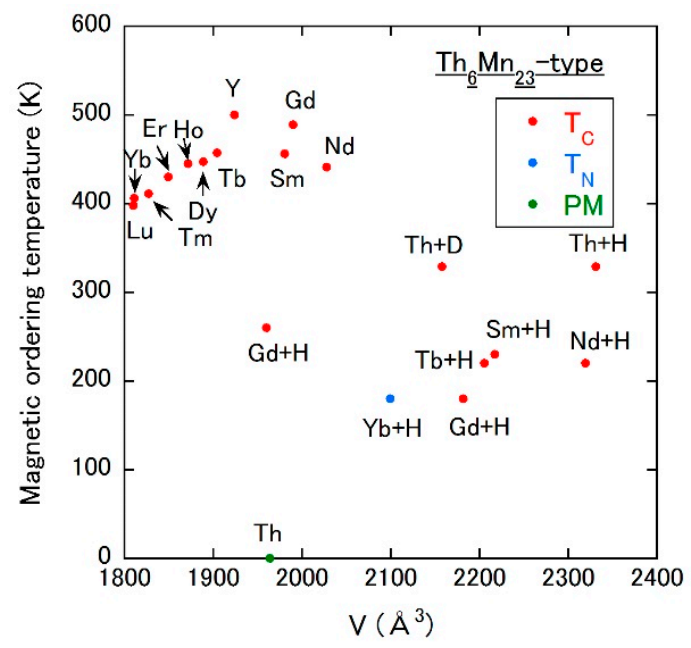

Figure 2. Magnetic ordering temperature vs. unit cell volume plot of $\mathrm{Th}_{6} \mathrm{Mn}_{23}$-type $\mathrm{Mn}$ compounds. $T_{\mathrm{N}}$ is the Néel temperature. PM means the paramagnetic state. For example, $\mathrm{Th}+\mathrm{H}(\mathrm{Th}+\mathrm{D})$ means the hydrogen (deuterium)-absorbed $\mathrm{Th}_{6} \mathrm{Mn}_{23}$.

\subsection{Carbon-Added $\mathrm{Mn}_{5} \mathrm{Si}_{3}$}

This system shows a change from the AFM to FM state by the carbon addition. The hexagonal $\mathrm{Mn}_{5} \mathrm{Si}_{3}$-type structure is known as a superior platform for studying interstitial chemistry [43]. The space group is $P 6_{3} / \mathrm{mcm}$ (No. 193), in which the Wyckoff positions are the $4 d$ for Mn1, the $6 g$ for Mn2 and the $6 g$ for Si (see also Figure 3a). Carbon atoms occupy the $2 b$ site. While the parent compound $\mathrm{Mn}_{5} \mathrm{Si}_{3}$ shows an AFM ordering at the Néel temperature $T_{\mathrm{N}}=98 \mathrm{~K}$, a thin film $\mathrm{Mn}_{5} \mathrm{Si}_{3} \mathrm{C}_{\mathrm{x}}$ becomes a room-temperature ferromagnet with $T_{C}=350 \mathrm{~K}$ as shown in Figure $3 \mathrm{~b}$ (see the filled squares) $[44,45]$. In [44], the appearance of the FM state is ascribed to the enhanced Mn-Mn interaction mediated by added carbon. Associated with the unit cell volume expansion by the carbon addition, the saturation Mn moment rapidly increases to $1 \mu_{\mathrm{B}} / \mathrm{Mn}$ at $\mathrm{x}=0.75$ (see Figure $3 \mathrm{c}$ ). However, the $\mathrm{x}$ dependence of $T_{C}$ is peculiar: a $T_{C}$ plateau of $350 \mathrm{~K}$ in a rather wide $x$ range, where the saturation $\mathrm{Mn}$ moment is steadily reduced as $\mathrm{x}$ is increased above 0.75 . We speculate that the hybridization between $\mathrm{Mn} 2$ and $\mathrm{C}$ atoms is strong, due to the short Mn2-C distance (see Figure 3a). As $\mathrm{x}$ is increased, the magnetic moment of Mn2 would be decreased, but that of Mn1 under well localized state due to the weak influence of the carbon addition would be enhanced. The rather strong Mn1-Mn1 magnetic interaction would be responsible for the plateau of $T_{C}$, while the decreasing Mn2 moment with increasing x would contribute to the reduction in the saturation moment.

\section{4. ( $\mathrm{R}$ or Actinide) $\mathrm{Mn}_{2} \mathrm{Si}_{2}$ and Its Germanides}

Despite the absence of a report on the addition of light elements in these compounds, the magnetic ordering temperature vs. unit cell volume plot shows the thought-provoking results as shown in Figure 4. These compounds possess the tetragonal $\mathrm{ThCr}_{2} \mathrm{Si}_{2}$-type structure (I4/mmm, No. 139), where $\mathrm{Mn}$ atoms at the $4 d$ sites form the layered structure perpendicular to the $c$ axis. R (Actinide) and $\mathrm{Si}(\mathrm{Ge})$ atoms occupy the $2 a$ and the $4 e$ sites, respectively. In the case of $\mathrm{RMn}_{2} \mathrm{Si}_{2}$, only the $\mathrm{R}=\mathrm{La}$ compound exhibits an FM state and the other compounds AFM one (see 21-35 in Figure 4). When Si is replaced by Ge, FM (AFM) states are observed for $R=$ La to $S m(R=$ the other elements) as shown in 
36-47 of Figure 4. Figure 4 provides a good correlation between the magnetic ordering temperature and the unit cell volume throughout the two series: systematically descending ordering temperature with expanding volume. Furthermore, magnetic structure changes from AFM to FM at approximately $179 \AA^{3}$, which is consistent with the picture of the Bethe-Slater curve. The inverse trend is confirmed in (U or Th) $\mathrm{Mn}_{2} \mathrm{Si}_{2}$ and its germanide (see 48 and 49 (50 and 51) in Figure 4), that is, the crossover from the FM to AFM state occurs by increasing the volume in each system. This can be ascribed to the difference of valence between rare-earth (trivalent) and actinide (maybe tetravalent) elements as in the case of $\mathrm{Th}_{6} \mathrm{Mn}_{23}$-type compounds.

(a)

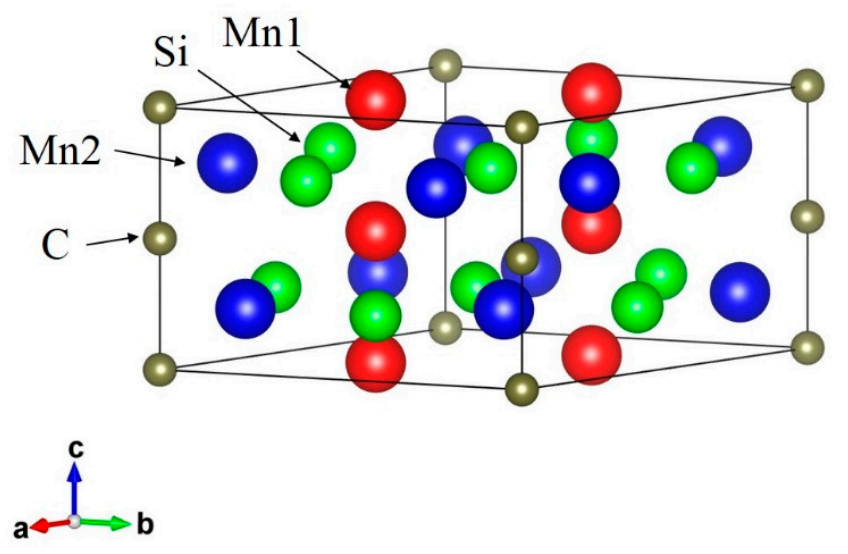

(b)

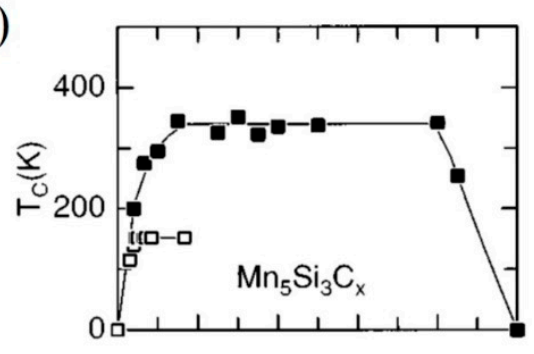

(c)

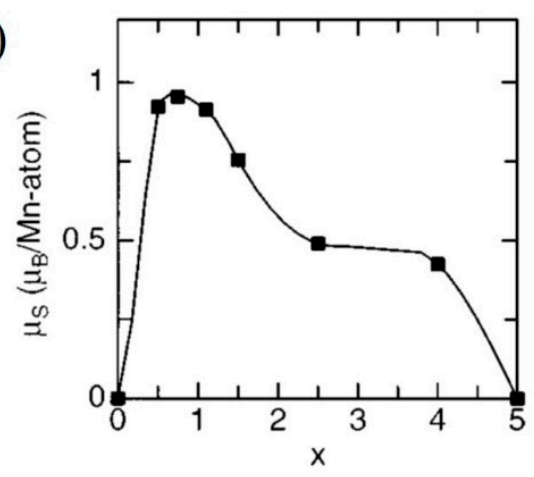

Figure 3. (a) Crystal structure of $\mathrm{Mn}_{5} \mathrm{Si}_{3} \mathrm{C}_{\mathrm{x}}$, where the solid line represents the unit cell. $\mathrm{x}$ dependence of $(\mathbf{b}) T_{C}$ and (c) the saturation magnetic moment for $\mathrm{Mn}_{5} \mathrm{Si}_{3} \mathrm{C}_{\mathbf{x}}$. In (b) , the filled and the open squares indicate the thin film and bulk samples, respectively. Reproduced with permission from [44].

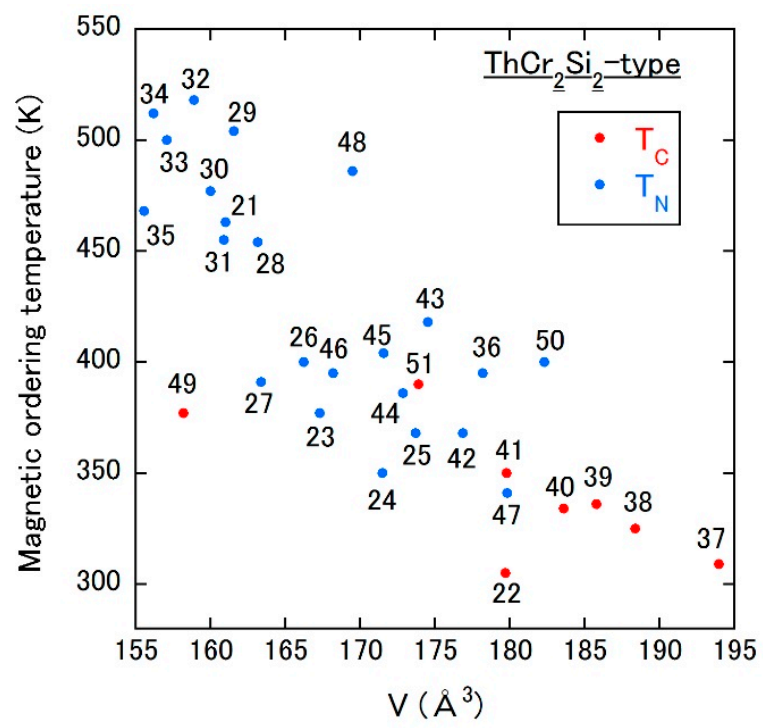

Figure 4. Magnetic ordering temperature vs. unit cell volume plot of $\mathrm{ThCr}_{2} \mathrm{Si}_{2}$-type Mn compounds. The numbers in the figure correspond to those in Table 4 (21-47 for R-containing compounds, and 48-51 for U- or Th-containing compounds). 


\subsection{Boron-Added $P d_{0.75} M n_{0.25}$ Alloy}

The disordered face-centered-cubic (fcc) $\mathrm{Pd}_{1-x} \mathrm{Mn}_{\mathrm{x}}$ alloys are the well studied spin-glass system [46]. The crystal structure is described by the space group of $F m \overline{3} m$ (No. 225), possessing only the $4 a$ site (see Figure 5), that is randomly occupied by $\mathrm{Pd}$ and Mn atoms. At $x=0.25$, the spin-glass transition temperature $T_{\mathrm{SG}}$ is $45 \mathrm{~K}$ [47]. The $\mathrm{Pd}_{0.75} \mathrm{Mn}_{0.25}$ alloy can incorporate boron atoms $[48,49]$ with the solubility limit of approximately $\mathrm{x} \sim 0.16$ in $\mathrm{Pd}_{0.75} \mathrm{Mn}_{0.25} \mathrm{~B}_{\mathrm{x}}$. According to the structure report [50] of $\mathrm{PdH}_{\mathrm{x}}$ with the same structure, interstitial atoms prefer the octahedral sites (the $4 b$ site, see Figure 5). The volume expansion occurs with the increase of $x$ as shown in Table 2. Figure 6a shows the isothermal magnetization curves of $\mathrm{Pd}_{0.75} \mathrm{Mn}_{0.25} \mathrm{~B}_{\mathrm{x}}$ at room temperature, which demonstrate the emergence of room temperature ferromagnetism by the slight addition of boron atoms. To elucidate the impact of the boron addition on the effective magnetic moment of Mn atoms, temperature dependences of inverse dc magnetization $1 / \chi_{\mathrm{dc}}$ are measured as shown in Figure $6 \mathrm{~b}$. All measured samples follow the Curie-Weiss law above $T_{C}$ (see the solid lines in Figure $6 \mathrm{~b}$, and the extracted effective magnetic moment $\mu_{\text {eff }}$ and the Weiss temperature $\theta$ are summarized in Table 2). $\mu_{\text {eff }}$ of the parent compound is $4.85 \mu_{\mathrm{B}} / \mathrm{Mn}$, which is once reduced by the boron addition, that is a signature of hybridization between the $\mathrm{Mn}$ and boron atoms. However, the value grows with increasing $T_{\mathrm{C}}$ up to $390 \mathrm{~K}$, which is the maximum value in this system. Furthermore, $\mu_{\text {eff }}$ is comparable to the saturation moment in Figure $6 a$. These facts suggest that the hybridization would be rather weak due to the wide space of the octahedral cavity and/or the rather low occupancy derived from being born at the octahedral site (e.g., $12.5 \%$ at $\mathrm{x}=0.125$ ). In the latter case, a Mn atom near the boron atom possesses a reduced magnetic moment and that with no neighboring boron atom would show an enhanced moment. Above $x=0.148$, both $T_{C}$ and $\mu_{\text {eff }}$ are reduced, which designates the dominating orbital hybridization between $\mathrm{Mn}$ and boron atoms, which is also consistent with the small change in the unit cell volume.

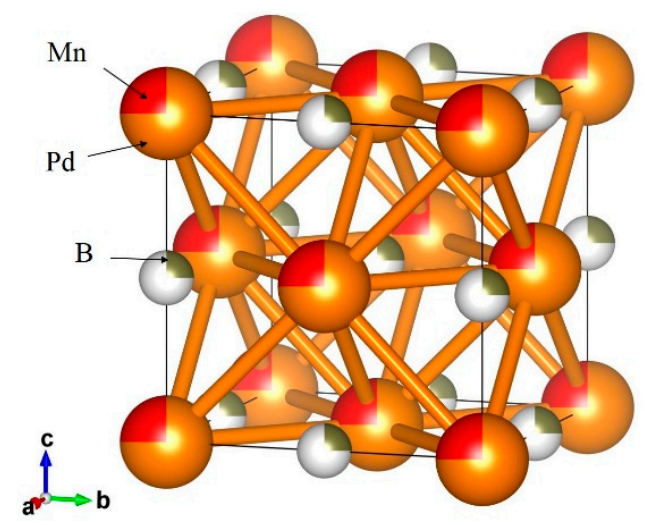

Figure 5. Crystal structure of $\operatorname{Pd}_{0.75} \mathrm{Mn}_{0.25} \mathrm{~B}_{\mathrm{x}}$. The solid line represents the unit cell.

Table 2. Lattice parameter, unit cell volume, $\mu_{\text {eff }}, \theta$ and $T_{C}$ of $\operatorname{Pd}_{0.75} M_{0.25} B_{x}$.

\begin{tabular}{cccccc}
\hline $\mathbf{x}$ & $\boldsymbol{a}(\mathbf{\AA})$ & $\boldsymbol{V}\left(\AA^{3}\right)$ & $\mu_{\text {eff }}\left(\boldsymbol{\mu}_{\mathbf{B}} / \mathbf{M n}\right)$ & $\boldsymbol{\theta}(\mathbf{K})$ & $\boldsymbol{T}_{\mathbf{C}}(\mathbf{K})$ \\
\hline 0 & 3.909 & 59.7 & 4.85 & -94 & - \\
0.015 & 3.916 & 60.1 & 2.01 & 218 & 325 \\
0.055 & 3.925 & 60.5 & 2.84 & 333 & 340 \\
0.070 & 3.936 & 61.0 & 3.31 & 355 & 339 \\
0.105 & 3.988 & 63.4 & 3.09 & 384 & 374 \\
0.125 & 4.008 & 64.4 & 3.40 & 394 & 390 \\
0.148 & 4.026 & 65.3 & 3.72 & 313 & 330 \\
0.155 & 4.031 & 65.5 & 1.23 & 291 & 252 \\
0.168 & 4.020 & 65.0 & 1.26 & 296 & 256 \\
\hline
\end{tabular}



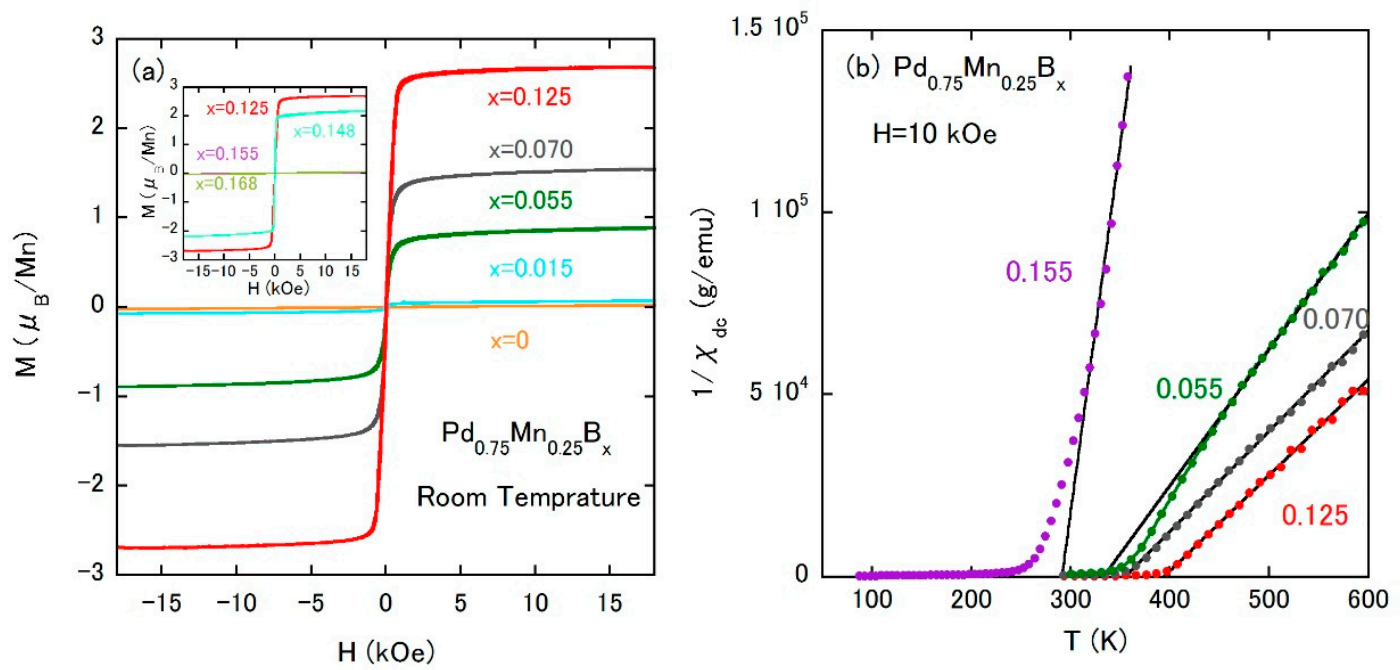

Figure 6. (a) Isothermal magnetization curves of $\mathrm{Pd}_{0.75} \mathrm{Mn}_{0.25} \mathrm{~B}_{\mathrm{x}}$ at room temperature. Reproduced with permission from [49]; (b) temperature dependences of the inverse $\chi_{\mathrm{dc}}$ of $\operatorname{Pd}_{0.75} \mathrm{Mn}_{0.25} \mathrm{~B}_{\mathrm{x}}$. The external field is $10 \mathrm{kOe}$.

The magnetic phase diagram is constructed as shown in Figure 7a,b. At lower $\mathrm{x}$, a coexistence of the fcc phase and the ordered derivative phase $\left(\mathrm{AuCu}_{3}\right)$ of fcc occurs $[48,49]$. The latter phase is responsible for another magnetic ordering at $T_{M}$ [49]. The spin-glass state survives under the emergence of FM state, and both ordering temperatures seem to compete with each other. Therefore, this system is considered to be the typical Mn-based compound presenting the additional formation of the FM state, coexisting with the spin-glass state of Mn atoms at low temperatures. Figure $7 \mathrm{c}$ displays the relationship between the $T_{C}$ and the unit cell volume. The vertical blue line is drawn at the volume of the parent compound showing only the spin-glass state. A linear correlation between the $T_{C}$ and the unit cell volume in the region of $V=60-64 \AA^{3}$ indicates a $T_{C}$ higher than $300 \mathrm{~K}$ even at the blue line, which means a possible abrupt birth of FM exchange coupling.
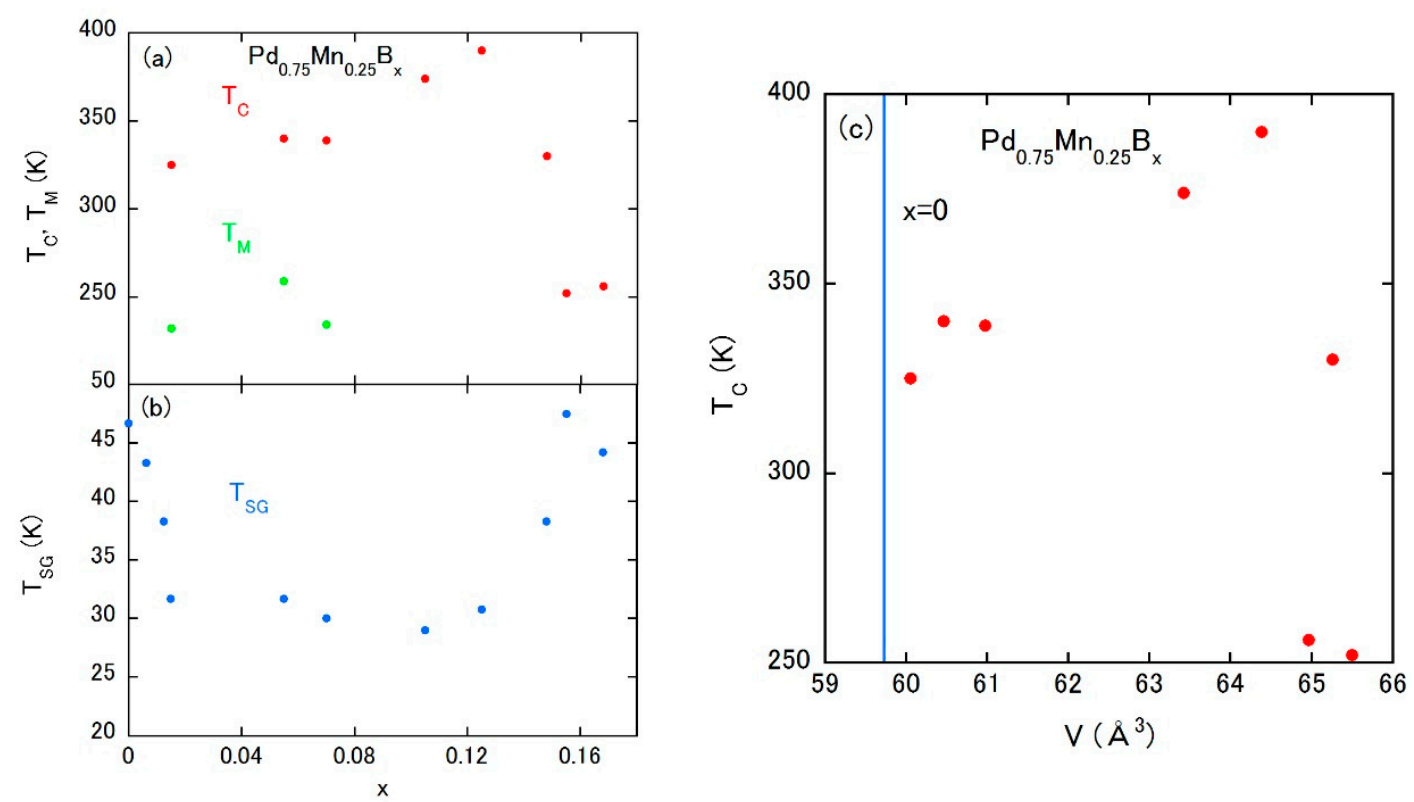

Figure 7. (a,b) Magnetic phase diagram of $\mathrm{Pd}_{0.75} \mathrm{Mn}_{0.25} \mathrm{~B}_{\mathrm{x}}$; (c) $T_{\mathrm{C}}$ vs. $V$ plot of $\mathrm{Pd}_{0.75} \mathrm{Mn}_{0.25} \mathrm{~B}_{\mathrm{x}}$.

We remarked on the transport properties of $\mathrm{Pd}_{0.75} \mathrm{Mn}_{0.25} \mathrm{~B}_{\mathrm{x}}$. Figure 8 shows the temperature dependences of electrical resistivity, which highlight the rather large temperature dependence 
below $T_{C}$ even in the disordered alloy. Considering that the spin-glass parent compound shows a weak temperature dependence, the FM interaction might produce some coherence effect on the electrical conductivity.

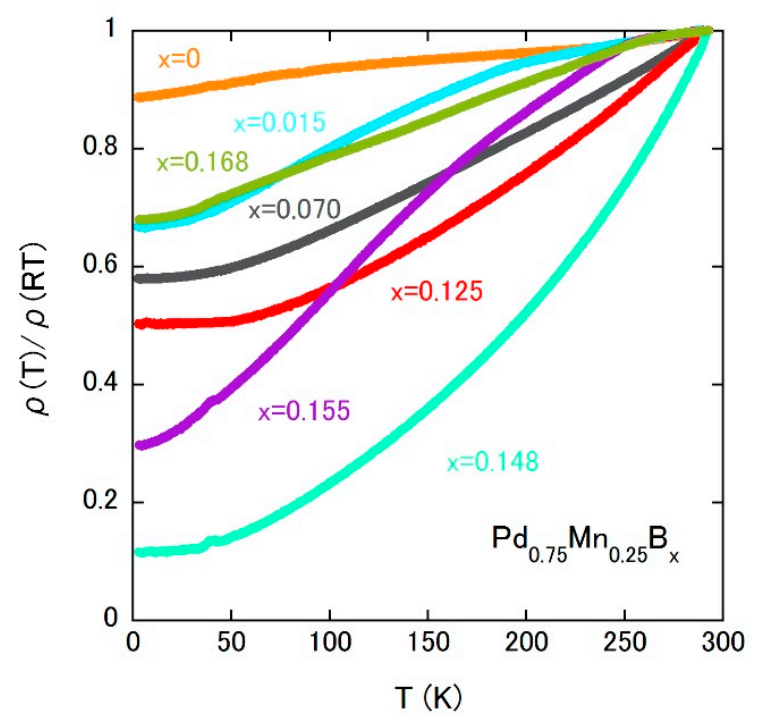

Figure 8. Temperature dependences of the electrical resistivity of $\operatorname{Pd}_{0.75} \mathrm{Mn}_{0.25} \mathrm{~B}_{\mathrm{x}}$.

\subsection{Boron-Added $\mathrm{Sm}_{2} \mathrm{Mn}_{8} \mathrm{Al}{ }_{9}$}

$\mathrm{Sm}_{2} \mathrm{Mn}_{8} \mathrm{Al}_{9}$ is isostructural to $\mathrm{R}_{2} \mathrm{Fe}_{17} \mathrm{~N}_{\mathrm{x}}$, as mentioned in Section 2.1, and allows the interstitial $\mathrm{B}$ atoms at the $9 e$ site (see Figure 9) [51]. In the present case, $\mathrm{Mn}$ and $\mathrm{Al}$ atoms randomly occupy the $\mathrm{Zn}$ sites of hexagonal $\mathrm{Th}_{2} \mathrm{Zn}_{17}$-type structure (space group: $R \overline{3} m$, No. 166). There is only one Wyckoff position $6 c$ for Sm atoms, but Mn and $\mathrm{Al}$ atoms have four Wyckoff positions $6 c, 9 d, 18 f$ and 18h, which are tentatively represented by Mn1, Mn2, Mn3 and Mn4, respectively, in Figure 9. The boron concentration dependences of lattice parameters and unit cell volume for $\mathrm{Sm}_{2} \mathrm{Mn}_{8} \mathrm{Al}_{9} \mathrm{~B}_{\mathrm{x}}$, determined with the help of the Rietveld refinement program [52], are listed in Table 3. The solubility limit would be $\mathrm{x} \sim 1 . \Delta V / V$ at $\mathrm{x} \geq 0.1$ is much smaller than that of $\operatorname{Pd}_{0.75} \mathrm{Mn}_{0.25} \mathrm{~B}_{\mathrm{x}}$, which suggests the stronger orbital hybridization between $\mathrm{Mn}$ and boron atoms in $\mathrm{Sm}_{2} \mathrm{Mn}_{8} \mathrm{Al}_{9} \mathrm{~B}_{\mathrm{x}}$ (see also Section 2.4). We note here that the nearest neighbor atoms of boron are Mn3 and Mn4, which amount to $71 \%$ of all Mn atoms (see also Figure 9). This may lead to a large increase in hybridization under a small variation of volume by the interstitial atoms.

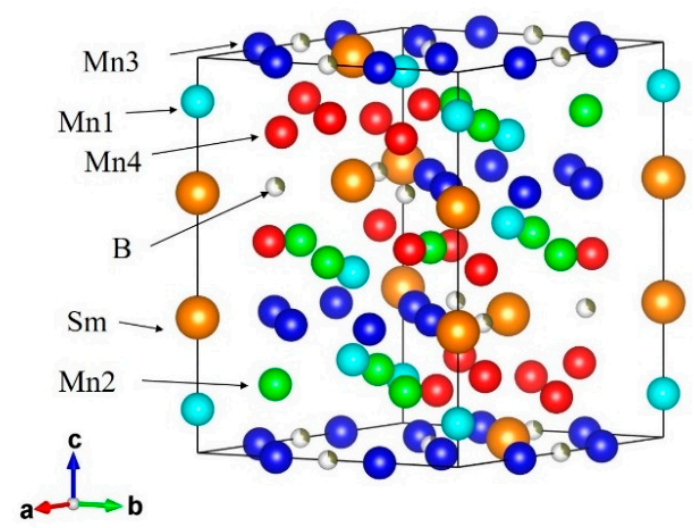

Figure 9. Crystal structure of $\mathrm{Sm}_{2} \mathrm{Mn}_{8} \mathrm{Al}_{9} \mathrm{~B}_{\mathrm{x}}$; the solid line represents the unit cell. 
Table 3. Lattice parameter, unit cell volume, $\mu_{\text {eff, }} \theta$ and $T_{C}$ due to Mn moments of $\mathrm{Sm}_{2} \mathrm{Mn}_{8} \mathrm{Al}_{9} \mathrm{~B}_{\mathrm{x}}$. Assuming that a negligible contribution of the Sm magnetic moment is usually smaller than the Mn moment value, $\mu_{\text {eff }}$ is calculated.

\begin{tabular}{ccccccc}
\hline $\mathbf{x}$ & $\boldsymbol{a}(\AA)$ & $\boldsymbol{c}(\AA)$ & $\boldsymbol{V}\left(\AA^{3}\right)$ & $\mu_{\text {eff }}\left(\mu_{\mathrm{B}} / \mathbf{M n}\right)$ & $\boldsymbol{\theta}(\mathbf{K})$ & $\boldsymbol{T}_{\mathbf{C}}$ due to $\mathbf{M n}(\mathbf{K})$ \\
\hline 0 & 8.970 & 13.109 & 913.5 & 2.89 & -212 & - \\
0.1 & 8.958 & 13.091 & 909.7 & 2.91 & 15 & $415(20)$ \\
0.5 & 8.958 & 13.093 & 910.0 & 1.34 & 443 & $408(10)$ \\
0.75 & 8.966 & 13.100 & 912.0 & 1.84 & 453 & $404(5)$ \\
1 & 8.975 & 13.112 & 914.6 & 0.98 & 489 & 437 \\
\hline
\end{tabular}

The isothermal magnetization curves are measured at room temperature as shown in Figure 10a, which have revealed the abrupt emergence of ferromagnetism at even a small amount of boron atoms. The temperature dependences of $1 / \chi_{\mathrm{dc}}$ demonstrate that boron-added samples follow the Curie-Weiss law above $T_{C}$ (see the solid lines in Figure 10b). $\mathrm{Sm}_{2} \mathrm{Mn}_{8} \mathrm{Al}_{9}$ shows a FM behavior below approximately $100 \mathrm{~K}$. Taking into account that the La-counterpart does not show a magnetic ordering at that temperature (see the ac magnetization $\chi_{\mathrm{ac}}$ results in the inset of Figure 10b), the low-temperature magnetic transition in the parent compound is due to Sm ions. The $\mu_{\text {eff }}$ and Weiss temperature of each sample are summarized in Table 3 . As $\mathrm{x}$ is increased, $\mu_{\text {eff }}$ is rapidly reduced, which is indicative of strong orbital hybridization, which is also supported by the weak $x$ dependence of the unit cell volume. It is to be pointed out that the paramagnetic Mn moment abruptly forms the FM state at room temperature even when the density of boron atoms is substantially low. Under a strong orbital hybridization between $\mathrm{Mn}$ and boron atoms, the lattice expansion might not be essential for the formation of FM coupling at room temperature.
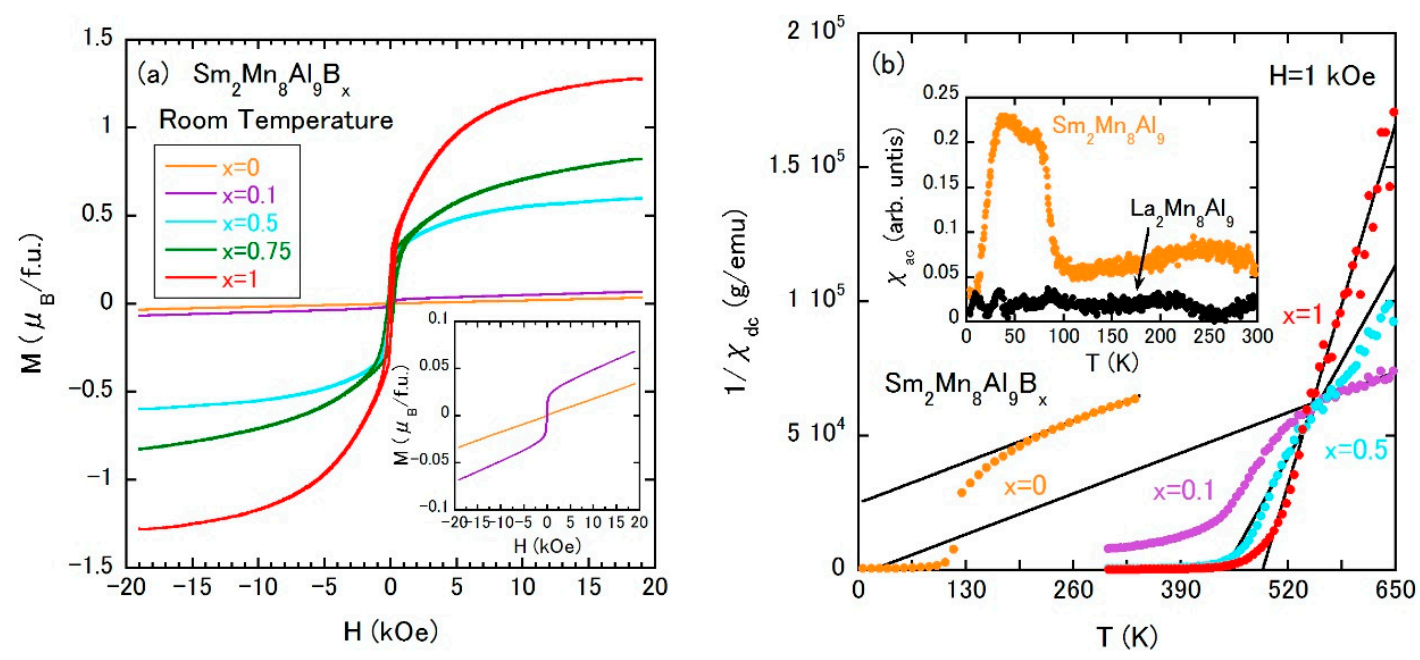

Figure 10. (a) Isothermal magnetization curves of $\mathrm{Sm}_{2} \mathrm{Mn}_{8} \mathrm{Al}_{9} \mathrm{~B}_{\mathrm{x}}$ at room temperature; (b) temperature dependences of the inverse $\chi_{\mathrm{dc}}$ of $\mathrm{Sm}_{2} \mathrm{Mn}_{8} \mathrm{Al}_{9} \mathrm{~B}_{\mathrm{x}}$. The external field is $1 \mathrm{kOe}$, the inset is the temperature dependences of $\chi_{\mathrm{ac}}$ of $\mathrm{Sm}_{2} \mathrm{Mn}_{8} \mathrm{Al}_{9}$ and $\mathrm{La}_{2} \mathrm{Mn}_{8} \mathrm{Al}_{9}$.

The magnetic properties of $\mathrm{Sm}_{2} \mathrm{Mn}_{8} \mathrm{Al}_{9} \mathrm{~B}_{\mathrm{x}}$ are summarized as a magnetic phase diagram in Figure 11a. The $\chi_{\mathrm{ac}}(\mathrm{T})$ measurements indicate the survival of magnetic ordering due to Sm ions at approximately $85 \mathrm{~K}$, which is independent of the room temperature FM state and seems to disappear at $x=1$. The high-temperature $T_{C}$ due to Mn atoms shows a shallow minimum at $x=0.75$. The inset of Figure 11a is the high-temperature $T_{C}$ vs. $V$ plot, in which $V$ at $x=0$ is denoted by the vertical blue line as in Figure 7c. The observation of room temperature ferromagnetism at both sides of the vertical line strongly suggests that the birth of room temperature FM coupling between Mn atoms is 
not related to the volume change. The effect of volume change, as studied well in rare-earth Fe-based magnets, is triggered by the appearance of the FM state due to Mn atoms.
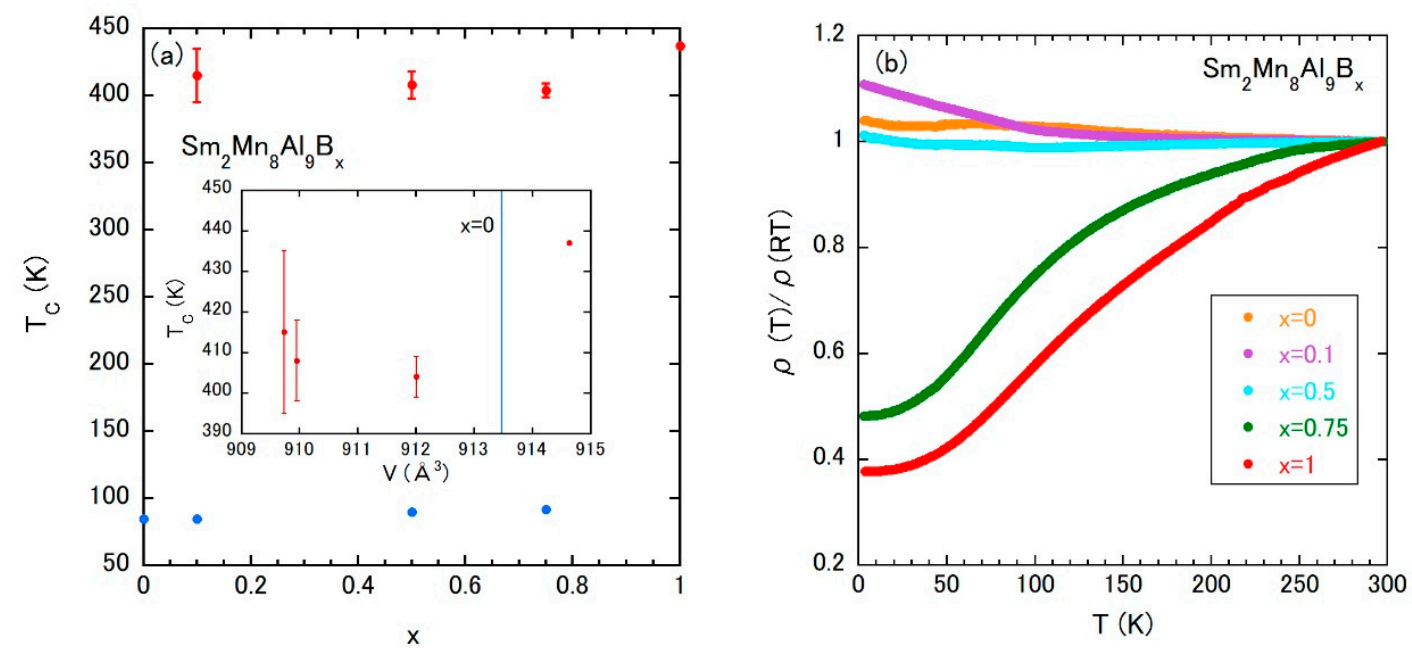

Figure 11. (a) Magnetic phase diagram of $\mathrm{Sm}_{2} \mathrm{Mn}_{8} \mathrm{Al}_{9} \mathrm{~B}_{\mathrm{x}}$; the inset is $T_{\mathrm{C}}$ vs. $V$ plot of $\mathrm{Sm}_{2} \mathrm{Mn}_{8} \mathrm{Al}_{9} \mathrm{~B}_{\mathrm{x}}$; and (b) temperature dependences of electrical resistivity of $\mathrm{Sm}_{2} \mathrm{Mn}_{8} \mathrm{Al}_{9} \mathrm{~B}_{\mathrm{x}}$.

The temperature dependence of $\rho$ exhibits a drastic change as shown in Figure $11 \mathrm{~b}$. The carriers would show a localized nature up to $\mathrm{x}=0.5$, however, metallic behavior is observed above $\mathrm{x}=0.75$. The localized behavior is also reported in isostructural Mn compounds [53] such as $\mathrm{Gd}_{2} \mathrm{Mn}_{\mathrm{x}} \mathrm{Al}_{17-\mathrm{x}}$ and $\mathrm{Tb}_{2} \mathrm{Mn}_{\mathrm{x}} \mathrm{Al}_{17-\mathrm{x}}$. The shift to the itinerant $\mathrm{Mn}$ moment with increasing $\mathrm{x}$ and/or some coherence effect of the FM Mn-moment observed in $\mathrm{Pd}_{0.75} \mathrm{Mn}_{0.25} \mathrm{~B}_{\mathrm{x}}$ would be responsible for the metallic temperature dependence.

\subsection{Brief Summary of Mn-Based Compounds}

As in the rare-earth Fe-based compounds, the interstitial atoms give rise to the enhancement of FM interaction in the weak hybridization regime leading to the appearance of room temperature ferromagnetism. However, the Mn compounds surveyed above manifest the change or additional formation of magnetism by the interstitial atoms, while many rare-earth Fe-based parent compounds are already ferromagnets. The change from paramagnetic to FM state is observed in hydrogen-absorbed $\mathrm{Th}_{6} \mathrm{Mn}_{23}$, hydrogen-absorbed $\mathrm{YMn}_{2}$ or $\mathrm{Sm}_{2} \mathrm{Mn}_{8} \mathrm{Al}_{9} \mathrm{~B}_{\mathrm{x}}$. The result of $\mathrm{Mn}_{5} \mathrm{Si}_{3} \mathrm{C}_{\mathrm{x}}$ thin film may be a rare example of change from the AFM to FM state by the interstitial atoms. In $\mathrm{Pd}_{0.75} \mathrm{Mn}_{0.25} \mathrm{~B}_{\mathrm{x}}$, the room temperature ferromagnetism is induced by a slight addition of boron, while the low-temperature magnetic ground state of the parent compound is unchanged. This can be regarded as an example of the additional formation of magnetism by interstitial atoms. It should be noted that, in some cases, the change or additional formation of a magnetic state seems to abruptly occur, which is valuable for future research. We note here that the magnetic structures have been divided into FM and AFM, although some compounds may show a more complicated state such as canted AFM, and spiral AFM. In the future, discussion taking into account a more microscopic mechanism of the magnetic ordering would be necessary.

We add the comment on Mn-based Heusler compounds, which show a rich variety of physical properties such as the topological Hall effect, shape-memory and so on [54-56]. While many Mn-based Heusler compounds show ferromagnetism, a Heusler compound, allowing interstitial atoms, has not been reported to our knowledge. 


\subsection{Candidate Showing a Change in Magnetism by Interstitial Atoms}

Mn compounds may be a superior platform to examine the change in the magnetic state or the additional formation of new magnetic coupling by interstitial atoms. We noted that, in some cases, the change to FM state or the additional formation of the FM state would occur irrespectively of interstitial atom-induced volume change. Notwithstanding, hereafter, we continue to discuss, based on the unit cell volume, because the results of $\mathrm{Mn}_{5} \mathrm{Si}_{3} \mathrm{C}_{\mathrm{x}}, \mathrm{Pd}_{0.75} \mathrm{Mn}_{0.25} \mathrm{~B}_{\mathrm{x}}$ and $\mathrm{Sm}_{2} \mathrm{Mn}_{8} \mathrm{Al}_{9} \mathrm{~B}_{\mathrm{x}}$ are not well analyzed systematically by comparing several compounds with the same crystal structure. In other words, the magnetic ordering temperature vs. unit cell volume plot as shown in Figure 2 could not be constructed due to the absence of well investigated other Mn compounds in these crystal structures. Therefore, at the present stage, we believe that it is still valuable to survey the magnetic structures of compounds using the unit cell volumes. In this subsection, especially bearing a change in magnetism by interstitial atoms in mind, we seek a qualifying Mn compound using the magnetic ordering temperature vs. a unit cell volume plot. We selected the crystal structures allowing the site occupation of interstitial atoms: $\mathrm{Ni}_{3} \mathrm{Sn}, \mathrm{ThMn}_{12}, \mathrm{Fe}_{2} \mathrm{P}, \mathrm{Ni}_{2} \mathrm{In}, \mathrm{LiAlSi}$, TiNiSi, $\mathrm{AuCu}$ and $\mathrm{Cu}_{2} \mathrm{Sb}$-type structures.

\subsection{1. $\mathrm{Ni}_{3} \mathrm{Sn}$-Type Structure}

This hexagonal structure $\left(P 6_{3} / m m c\right.$, No. 194) is recently attractive as a topological AFM substance [20] represented by $\mathrm{Mn}_{3} \mathrm{Sn}$. All $\mathrm{Ni}_{3} \mathrm{Sn}$-type compounds displayed in Figure 12a possess only one crystallographic $6 h$ site for the Mn atom. As seen in Figure 12a, only the AFM state has been observed and a change to FM state would be difficult.
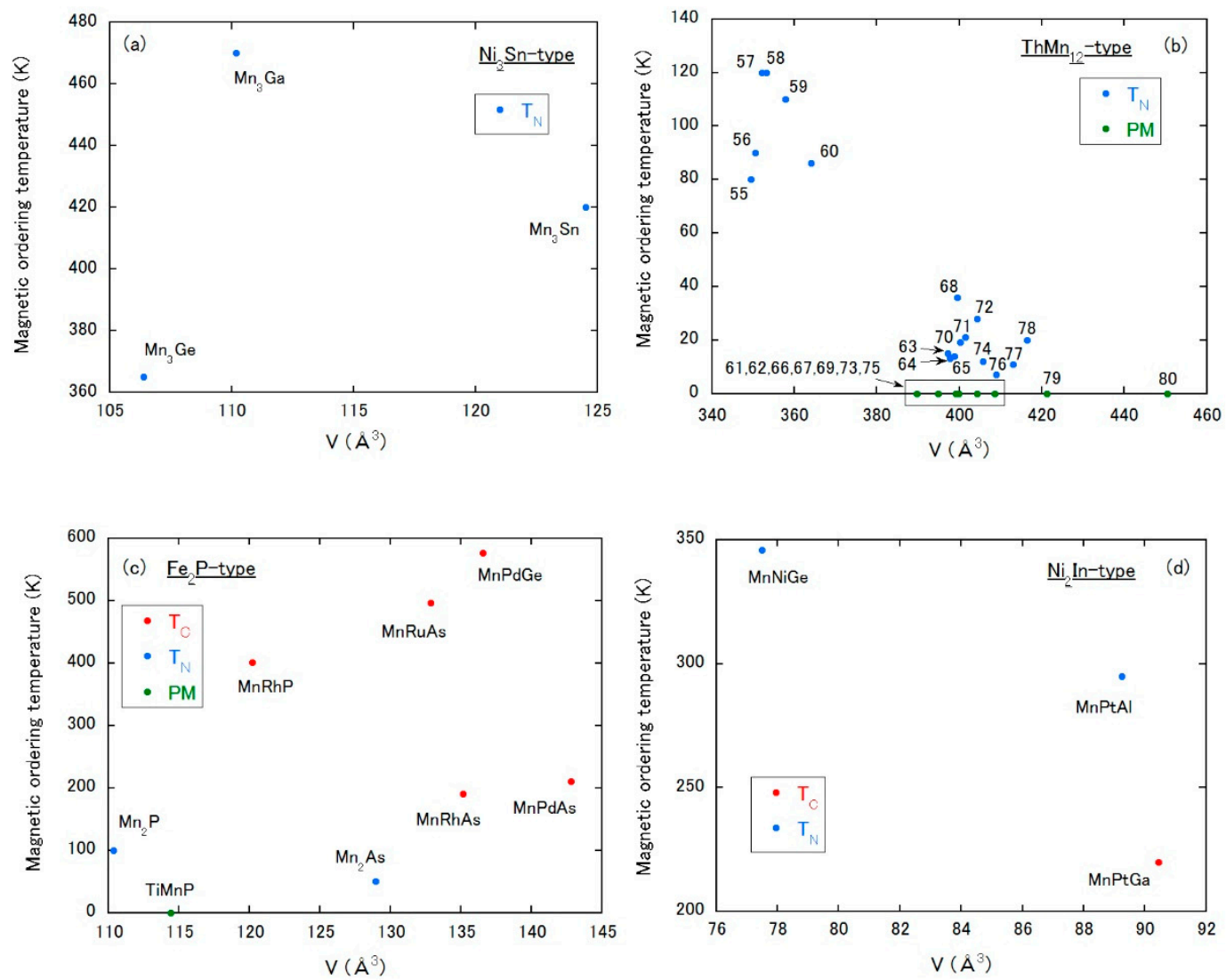

Figure 12. Magnetic ordering temperature vs. unit cell volume plot of Mn-based compounds with (a) $\mathrm{Ni}_{3} \mathrm{Sn}$-type, (b) $\mathrm{ThMn}_{12}$-type, (c) $\mathrm{Fe}_{2} \mathrm{P}$-type and (d) $\mathrm{Ni}_{2}$ In-type, respectively. PM means a paramagnetic state down to low temperatures. The numbers in (b) correspond to those in Table 4. 


\subsection{2. $\mathrm{ThMn}_{12}$-Type Structure}

The tetragonal $\mathrm{ThMn}_{12}$-type structure (I4/mmm, No. 139) is well studied in rare-earth Fe-based compounds (see Section 2.2). In the Mn compounds with this structure, Mn atoms occupy the $8 f, 8 i$, $8 j$ sites. As shown in Figure 12b, the magnetic properties are dominated by the AFM state. We note that, except for compounds No. 55-60, the AFM orderings of compounds containing rare-earth elements are triggered by the magnetic moments of rare-earth, and Mn atoms do not carry moments. Basically, with increasing volume, $T_{\mathrm{N}}$ tends to be suppressed. In this class of compounds, a change from AFM to a paramagnetic state of Mn atoms by interstitial atoms may be anticipated.

\subsection{3. $\mathrm{Fe}_{2} \mathrm{P}$-Type Structure}

The compounds with the hexagonal $\mathrm{Fe}_{2}$ P-type structure $(P \overline{6} 2 m$, No. 189) displayed in Figure $12 \mathrm{c}$ possess the $3 g$ site for the $\mathrm{Mn}$ atom, except $\mathrm{Mn}_{2} \mathrm{P}$ and $\mathrm{Mn}_{2} \mathrm{As}$, in which there exists the $3 g$ and $3 f$ sites for Mn atoms. Figure 12c indicates a possible crossover from paramagnetic to FM state across the volume of approximately $115-120 \AA^{3}$ for compounds with only the $3 g$ Mn site.

\subsection{4. $\mathrm{Ni}_{2} \mathrm{In}$-Type Structure}

The $\mathrm{Ni}_{2} \mathrm{In}$-type structure is hexagonal with the space group of $P 6_{3} / m m c$ (No. 194). Each compound has only one $\mathrm{Mn}$ site of the $2 a$. In this structure, $T_{\mathrm{N}}$ at a smaller volume tends to be suppressed as the volume is expanded and seems to transform to $T_{C}$ with further increasing volume (Figure 12d). The compounds with the $\mathrm{ThMn}_{12^{-}}$, the $\mathrm{Fe}_{2} \mathrm{P}$ - or the $\mathrm{Ni}_{2} \mathrm{In}$-type structure may be good candidates for examining a change in magnetic state by interstitial atoms as a function of the unit cell volume.

\subsubsection{LiAlSi-Type Structure}

This structure is cubic with the space group of $\bar{F} \overline{4} 3 m$ (No. 216). Each compound in Figure 13a possesses one Mn site with the $4 a, 4 b$ or $4 c$, depending on the literature. The magnetic ordering types of the cubic compounds would be classified by the VEC, which is different from the results of Figure 12a-d. The VEC values are denoted under the chemical formulae in Figure 13a. Except for the compounds with VEC $=7.7$ showing the AFM state, all compounds undergo FM as one. In FM compounds, $T_{C}$ tends to increase as the VEC is increased. If interstitial atoms change VEC from 7.33 to 7.7, a change between FM and AFM states might be possible, which may be a new phenomenon induced by interstitial atoms.

Table 4. Structural and magnetic properties of Mn-based compounds. $T_{\text {order }}$ is the magnetic ordering temperature. FM, AFM and PM mean ferromagnetic, antiferromagnetic and paramagnetic, respectively. Data are from the references listed in the table.

\begin{tabular}{cccccccccc}
\hline No. & Compound & $\begin{array}{c}\text { Structure } \\
\text { Type }\end{array}$ & $\boldsymbol{a}(\AA)$ & $\boldsymbol{b}(\mathbf{\AA})$ & $\boldsymbol{c}(\mathbf{\AA})$ & $\boldsymbol{V}\left(\AA^{3}\right)$ & $\begin{array}{c}\boldsymbol{T}_{\text {order }} \\
(\mathbf{K})\end{array}$ & Type & Ref. \\
\hline 1 & $\mathrm{Lu}_{6} \mathrm{Mn}_{23}$ & $\mathrm{Th}_{6} \mathrm{Mn}_{23}$ & 12.187 & 12.187 & 12.187 & 1810.0 & 398 & $\mathrm{FM}$ & {$[57]$} \\
2 & $\mathrm{Yb}_{6} \mathrm{Mn}_{23}$ & $\mathrm{Th}_{6} \mathrm{Mn}_{23}$ & 12.189 & 12.189 & 12.189 & 1810.9 & 406 & $\mathrm{FM}$ & {$[58]$} \\
3 & $\mathrm{Tm}_{6} \mathrm{Mn}_{23}$ & $\mathrm{Th}_{6} \mathrm{Mn}_{23}$ & 12.226 & 12.226 & 12.226 & 1827.5 & 411 & $\mathrm{FM}$ & {$[57]$} \\
4 & $\mathrm{Er}_{6} \mathrm{Mn}_{23}$ & $\mathrm{Th}_{6} \mathrm{Mn}_{23}$ & 12.275 & 12.275 & 12.275 & 1849.5 & 430 & $\mathrm{FM}$ & {$[57]$} \\
5 & $\mathrm{Ho}_{6} \mathrm{Mn}_{23}$ & $\mathrm{Th}_{6} \mathrm{Mn}_{23}$ & 12.324 & 12.324 & 12.324 & 1871.8 & 445 & $\mathrm{FM}$ & {$[57]$} \\
6 & $\mathrm{Dy}_{6} \mathrm{Mn}_{23}$ & $\mathrm{Th}_{6} \mathrm{Mn}_{23}$ & 12.361 & 12.361 & 12.361 & 1888.7 & 447 & $\mathrm{FM}$ & {$[57]$} \\
7 & $\mathrm{~Tb}_{6} \mathrm{Mn}_{23}$ & $\mathrm{Th}_{6} \mathrm{Mn}_{23}$ & 12.396 & 12.396 & 12.396 & 1904.8 & 457 & $\mathrm{FM}$ & {$[57]$} \\
8 & $\mathrm{Y}_{6} \mathrm{Mn}_{23}$ & $\mathrm{Th}_{6} \mathrm{Mn}_{23}$ & 12.438 & 12.438 & 12.438 & 1924.2 & 500 & $\mathrm{FM}$ & {$[59]$} \\
9 & $\mathrm{Gd}_{6} \mathrm{Mn}_{23} \mathrm{H}_{24}$ & $\mathrm{Th}_{6} \mathrm{Mn}_{23}$ & 12.515 & 12.515 & 12.515 & 1960.2 & 260 & $\mathrm{FM}$ & {$[60]$} \\
10 & $\mathrm{Th}_{6} \mathrm{Mn}_{23}$ & $\mathrm{Th}_{6} \mathrm{Mn}_{23}$ & 12.523 & 12.523 & 12.523 & 1963.9 & 0 & $\mathrm{PM}$ & {$[59]$} \\
11 & $\mathrm{Sm}_{6} \mathrm{Mn}_{23}$ & $\mathrm{Th}_{6} \mathrm{Mn}_{23}$ & 12.558 & 12.558 & 12.558 & 1980.4 & 456 & $\mathrm{FM}$ & {$[57]$} \\
12 & $\mathrm{Gd}_{6} \mathrm{Mn}_{23}$ & $\mathrm{Th}_{6} \mathrm{Mn}_{23}$ & 12.578 & 12.578 & 12.578 & 1989.9 & 489 & $\mathrm{FM}$ & {$[57]$} \\
13 & $\mathrm{Nd}_{6} \mathrm{Mn}_{23}$ & $\mathrm{Th}_{6} \mathrm{Mn}_{23}$ & 12.657 & 12.657 & 12.657 & 2027.6 & 441 & $\mathrm{FM}$ & {$[57]$} \\
\hline
\end{tabular}


Table 4. Cont.

\begin{tabular}{|c|c|c|c|c|c|c|c|c|c|}
\hline No. & Compound & $\begin{array}{c}\text { Structure } \\
\text { Type }\end{array}$ & $a(\AA)$ & $b(\AA ̊)$ & $c(\AA)$ & $V\left(\AA^{3}\right)$ & $\begin{array}{c}T_{\text {order }} \\
\text { (K) }\end{array}$ & Type & Ref. \\
\hline 14 & $\mathrm{Y}_{6} \mathrm{Mn}_{23} \mathrm{H}_{23}$ & $\mathrm{Th}_{6} \mathrm{Mn}_{23}$ & 12.805 & 12.805 & 12.805 & 2099.6 & 180 & AFM & [61] \\
\hline 15 & $\mathrm{Th}_{6} \mathrm{Mn}_{23} \mathrm{D}_{16}$ & $\mathrm{Th}_{6} \mathrm{Mn}_{23}$ & 12.922 & 12.922 & 12.922 & 2157.7 & 329 & FM & [62] \\
\hline 16 & $\mathrm{Gd}_{12} \mathrm{Mn}_{45} \mathrm{H}_{43}$ & $\mathrm{Th}_{6} \mathrm{Mn}_{23}$ & 12.97 & 12.97 & 12.97 & 2181.8 & 180 & $\mathrm{FM}$ & [63] \\
\hline 17 & $\mathrm{~Tb}_{6} \mathrm{Mn}_{23} \mathrm{H}_{23}$ & $\mathrm{Th}_{6} \mathrm{Mn}_{23}$ & 13.017 & 13.017 & 13.017 & 2205.6 & 220 & FM & [64] \\
\hline 18 & $\mathrm{Sm}_{6} \mathrm{Mn}_{23} \mathrm{H}_{24}$ & $\mathrm{Th}_{6} \mathrm{Mn}_{23}$ & 13.04 & 13.04 & 13.04 & 2217.3 & 230 & FM & [60] \\
\hline 19 & $\mathrm{Nd}_{6} \mathrm{Mn}_{23} \mathrm{H}_{24}$ & $\mathrm{Th}_{6} \mathrm{Mn}_{23}$ & 13.237 & 13.237 & 13.237 & 2319.4 & 220 & $\mathrm{FM}$ & [60] \\
\hline 20 & $\mathrm{Th}_{6} \mathrm{Mn}_{23} \mathrm{H}_{30}$ & $\mathrm{Th}_{6} \mathrm{Mn}_{23}$ & 13.259 & 13.259 & 13.259 & 2330.9 & 329 & FM & [59] \\
\hline 21 & $\mathrm{YMn}_{2} \mathrm{Si}_{2}$ & $\mathrm{ThCr}_{2} \mathrm{Si}_{2}$ & 3.924 & 3.924 & 10.457 & 161.0 & 463 & AFM & [65] \\
\hline 22 & $\mathrm{LaMn}_{2} \mathrm{Si}_{2}$ & $\mathrm{ThCr}_{2} \mathrm{Si}_{2}$ & 4.1151 & 4.1151 & 10.612 & 179.7 & 305 & FM & [65] \\
\hline 23 & $\mathrm{CeMn}_{2} \mathrm{Si}_{2}$ & $\mathrm{ThCr}_{2} \mathrm{Si}_{2}$ & 3.99 & 3.99 & 10.51 & 167.3 & 377 & AFM & [65] \\
\hline 24 & $\mathrm{PrMn}_{2} \mathrm{Si}_{2}$ & $\mathrm{ThCr}_{2} \mathrm{Si}_{2}$ & 4.03 & 4.03 & 10.559 & 171.5 & 350 & AFM & [65] \\
\hline 25 & $\mathrm{NdMn}_{2} \mathrm{Si}_{2}$ & $\mathrm{ThCr}_{2} \mathrm{Si}_{2}$ & 4.063 & 4.063 & 10.522 & 173.7 & 368 & AFM & [65] \\
\hline 26 & $\mathrm{SmMn}_{2} \mathrm{Si}_{2}$ & $\mathrm{ThCr}_{2} \mathrm{Si}_{2}$ & 3.975 & 3.975 & 10.52 & 166.2 & 400 & AFM & [65] \\
\hline 27 & $\mathrm{EuMn}_{2} \mathrm{Si}_{2}$ & $\mathrm{ThCr}_{2} \mathrm{Si}_{2}$ & 3.966 & 3.966 & 10.387 & 163.4 & 391 & AFM & [66] \\
\hline 28 & $\mathrm{GdMn}_{2} \mathrm{Si}_{2}$ & $\mathrm{ThCr}_{2} \mathrm{Si}_{2}$ & 3.948 & 3.948 & 10.468 & 163.2 & 454 & AFM & [65] \\
\hline 29 & $\mathrm{TbMn}_{2} \mathrm{Si}_{2}$ & $\mathrm{ThCr}_{2} \mathrm{Si}_{2}$ & 3.931 & 3.931 & 10.456 & 161.6 & 504 & AFM & [65] \\
\hline 30 & $\mathrm{DyMn}_{2} \mathrm{Si}_{2}$ & $\mathrm{ThCr}_{2} \mathrm{Si}_{2}$ & 3.915 & 3.915 & 10.44 & 160.0 & 477 & AFM & [65] \\
\hline 31 & $\mathrm{HoMn}_{2} \mathrm{Si}_{2}$ & $\mathrm{ThCr}_{2} \mathrm{Si}_{2}$ & 3.931 & 3.931 & 10.412 & 160.9 & 455 & AFM & [65] \\
\hline 32 & $\mathrm{ErMn}_{2} \mathrm{Si}_{2}$ & $\mathrm{ThCr}_{2} \mathrm{Si}_{2}$ & 3.905 & 3.905 & 10.42 & 158.9 & 518 & AFM & [65] \\
\hline 33 & $\mathrm{TmMn}_{2} \mathrm{Si}_{2}$ & $\mathrm{ThCr}_{2} \mathrm{Si}_{2}$ & 3.887 & 3.887 & 10.398 & 157.1 & 500 & AFM & [65] \\
\hline 34 & $\mathrm{YbMn}_{2} \mathrm{Si}_{2}$ & $\mathrm{ThCr}_{2} \mathrm{Si}_{2}$ & 3.877 & 3.877 & 10.391 & 156.2 & 512 & AFM & [65] \\
\hline 35 & $\mathrm{LuMn}_{2} \mathrm{Si}_{2}$ & $\mathrm{ThCr}_{2} \mathrm{Si}_{2}$ & 3.873 & 3.873 & 10.37 & 155.6 & 468 & AFM & [65] \\
\hline 36 & $\mathrm{YMn}_{2} \mathrm{Ge}_{2}$ & $\mathrm{ThCr}_{2} \mathrm{Si}_{2}$ & 4.0516 & 4.0516 & 10.854 & 178.2 & 395 & AFM & [65] \\
\hline 37 & $\mathrm{LaMn}_{2} \mathrm{Ge}_{2}$ & $\mathrm{ThCr}_{2} \mathrm{Si}_{2}$ & 4.195 & 4.195 & 11.022 & 194.0 & 309 & FM & [65] \\
\hline 38 & $\mathrm{CeMn}_{2} \mathrm{Ge}_{2}$ & $\mathrm{ThCr}_{2} \mathrm{Si}_{2}$ & 4.144 & 4.144 & 10.97 & 188.4 & 325 & $\mathrm{FM}$ & [65] \\
\hline 39 & $\mathrm{PrMn}_{2} \mathrm{Ge}_{2}$ & $\mathrm{ThCr}_{2} \mathrm{Si}_{2}$ & 4.123 & 4.123 & 10.929 & 185.8 & 336 & FM & [65] \\
\hline 40 & $\mathrm{NdMn}_{2} \mathrm{Ge}_{2}$ & $\mathrm{ThCr}_{2} \mathrm{Si}_{2}$ & 4.1022 & 4.1022 & 10.909 & 183.6 & 334 & FM & [65] \\
\hline 41 & $\mathrm{SmMn}_{2} \mathrm{Ge}_{2}$ & $\mathrm{ThCr}_{2} \mathrm{Si}_{2}$ & 4.062 & 4.062 & 10.896 & 179.8 & 350 & FM & [65] \\
\hline 42 & $\mathrm{GdMn}_{2} \mathrm{Ge}_{2}$ & $\mathrm{ThCr}_{2} \mathrm{Si}_{2}$ & 4.029 & 4.029 & 10.895 & 176.9 & 368 & AFM & [65] \\
\hline 43 & $\mathrm{TbMn}_{2} \mathrm{Ge}_{2}$ & $\mathrm{ThCr}_{2} \mathrm{Si}_{2}$ & 4.006 & 4.006 & 10.875 & 174.5 & 418 & AFM & [65] \\
\hline 44 & $\mathrm{DyMn}_{2} \mathrm{Ge}_{2}$ & $\mathrm{ThCr}_{2} \mathrm{Si}_{2}$ & 3.989 & 3.989 & 10.863 & 172.9 & 386 & AFM & [65] \\
\hline 45 & $\mathrm{HoMn}_{2} \mathrm{Ge}_{2}$ & $\mathrm{ThCr}_{2} \mathrm{Si}_{2}$ & 3.977 & 3.977 & 10.847 & 171.6 & 404 & AFM & [65] \\
\hline 46 & $\mathrm{ErMn}_{2} \mathrm{Ge}_{2}$ & $\mathrm{ThCr}_{2} \mathrm{Si}_{2}$ & 3.948 & 3.948 & 10.791 & 168.2 & 395 & AFM & [65] \\
\hline 47 & $\mathrm{YbMn}_{2} \mathrm{Ge}_{2}$ & $\mathrm{ThCr}_{2} \mathrm{Si}_{2}$ & 4.067 & 4.067 & 10.871 & 179.8 & 341 & AFM & [65] \\
\hline 48 & $\mathrm{ThMn}_{2} \mathrm{Si}_{2}$ & $\mathrm{ThCr}_{2} \mathrm{Si}_{2}$ & 4.0225 & 4.0225 & 10.475 & 169.5 & 486 & AFM & [65] \\
\hline 49 & $\mathrm{UMn}_{2} \mathrm{Si}_{2}$ & $\mathrm{ThCr}_{2} \mathrm{Si}_{2}$ & 3.922 & 3.922 & 10.284 & 158.2 & 377 & FM & [67] \\
\hline 50 & $\mathrm{ThMn}_{2} \mathrm{Ge}_{2}$ & $\mathrm{ThCr}_{2} \mathrm{Si}_{2}$ & 4.084 & 4.084 & 10.93 & 182.3 & 400 & AFM & [65] \\
\hline 51 & $\mathrm{UMn}_{2} \mathrm{Ge}_{2}$ & $\mathrm{ThCr}_{2} \mathrm{Si}_{2}$ & 4.012 & 4.012 & 10.803 & 173.9 & 390 & FM & [67] \\
\hline 52 & $\mathrm{Mn}_{3} \mathrm{Ge}^{2}$ & $\mathrm{Ni}_{3} \mathrm{Sn}$ & 5.338 & 5.338 & 4.312 & 106.4 & 365 & AFM & [68] \\
\hline 53 & $\mathrm{Mn}_{3} \mathrm{Ga}$ & $\mathrm{Ni}_{3} \mathrm{Sn}$ & 5.404 & 5.404 & 4.357 & 110.2 & 470 & AFM & [69] \\
\hline 54 & $\mathrm{Mn}_{3} \mathrm{Sn}$ & $\mathrm{Ni}_{3} \mathrm{Sn}$ & 5.64 & 5.64 & 4.52 & 124.5 & 420 & AFM & [20] \\
\hline 55 & $\mathrm{ErMn}_{12}$ & $\mathrm{ThMn}_{12}$ & 8.5719 & 8.5719 & 4.7553 & 349.4 & 80 & AFM & [70] \\
\hline 56 & $\mathrm{HoMn}_{12}$ & $\mathrm{ThMn}_{12}$ & 8.5817 & 8.5817 & 4.7592 & 350.5 & 90 & AFM & [71] \\
\hline 57 & $\mathrm{YMn}_{12}$ & $\mathrm{ThMn}_{12}$ & 8.597 & 8.597 & 4.7637 & 352.1 & 120 & AFM & [72] \\
\hline 58 & $\mathrm{TbMn}_{12}$ & $\mathrm{ThMn}_{12}$ & 8.6076 & 8.6076 & 4.7666 & 353.2 & 120 & AFM & [73] \\
\hline 59 & DyMn $_{12}$ & $\mathrm{ThMn}_{12}$ & 8.67 & 8.67 & 4.76 & 357.8 & 110 & AFM & [74] \\
\hline 60 & $\mathrm{GdMn}_{12}$ & $\mathrm{ThMn}_{12}$ & 8.673 & 8.673 & 4.839 & 364.0 & 86 & AFM & [74] \\
\hline 61 & $\mathrm{ScMn}_{4} \mathrm{Al}_{8}$ & $\mathrm{ThMn}_{12}$ & 8.7734 & 8.7734 & 5.0629 & 389.7 & 0 & PM & [75] \\
\hline 62 & $\mathrm{LuMn}_{4} \mathrm{Al}_{8}$ & $\mathrm{ThMn}_{12}$ & 8.814 & 8.814 & 5.083 & 394.9 & 0 & PM & [75] \\
\hline 63 & $\mathrm{ErMn}_{4} \mathrm{Al}_{8}$ & $\mathrm{ThMn}_{12}$ & 8.829 & 8.829 & 5.096 & 397.2 & 15 & AFM & [76] \\
\hline 64 & $\mathrm{TmMn}_{4} \mathrm{Al}_{8}$ & $\mathrm{ThMn}_{12}$ & 8.848 & 8.848 & 5.08 & 397.7 & 13 & AFM & [76] \\
\hline 65 & $\mathrm{HoMn}_{4} \mathrm{Al}_{8}$ & $\mathrm{ThMn}_{12}$ & 8.845 & 8.845 & 5.097 & 398.8 & 14 & AFM & [76] \\
\hline 66 & $\mathrm{UMn}_{4} \mathrm{Al}_{8}$ & $\mathrm{ThMn}_{12}$ & 8.8474 & 8.8474 & 5.0993 & 399.2 & 0 & $\mathrm{PM}$ & [77] \\
\hline 67 & $\mathrm{YMn}_{4} \mathrm{Al}_{8}$ & $\mathrm{ThMn}_{12}$ & 8.86 & 8.86 & 5.09 & 399.6 & 0 & PM & [76] \\
\hline 68 & $\mathrm{GdMn}_{6} \mathrm{Al}_{6}$ & $\mathrm{ThMn}_{12}$ & 8.845 & 8.845 & 5.108 & 399.6 & 36 & AFM & [78] \\
\hline 69 & $\mathrm{YbMn}_{4} \mathrm{Al}_{8}$ & $\mathrm{ThMn}_{12}$ & 8.854 & 8.854 & 5.102 & 400.0 & 0 & PM & [76] \\
\hline
\end{tabular}


Table 4. Cont.

\begin{tabular}{|c|c|c|c|c|c|c|c|c|c|}
\hline No. & Compound & $\begin{array}{c}\text { Structure } \\
\text { Type }\end{array}$ & $a(\AA)$ & $b(\AA ̊)$ & $c(\AA)$ & $V\left(\AA^{3}\right)$ & $\begin{array}{c}T_{\text {order }} \\
\text { (K) }\end{array}$ & Type & Ref. \\
\hline 70 & $\mathrm{DyMn}_{4} \mathrm{Al}_{8}$ & $\mathrm{ThMn}_{12}$ & 8.849 & 8.849 & 5.112 & 400.3 & 19 & AFM & [76] \\
\hline 71 & $\mathrm{TbMn}_{4} \mathrm{Al}_{8}$ & $\mathrm{ThMn}_{12}$ & 8.865 & 8.865 & 5.108 & 401.4 & 21 & AFM & [76] \\
\hline 72 & $\mathrm{GdMn}_{4} \mathrm{Al}_{8}$ & $\mathrm{ThMn}_{12}$ & 8.887 & 8.887 & 5.119 & 404.3 & 28 & AFM & [76] \\
\hline 73 & $\mathrm{TbMn}_{4.04} \mathrm{Al}_{7.96}$ & $\mathrm{ThMn}_{12}$ & 8.8885 & 8.8885 & 5.1179 & 404.3 & 0 & PM & [79] \\
\hline 74 & $\mathrm{SmMn}_{4} \mathrm{Al}_{8}$ & $\mathrm{ThMn}_{12}$ & 8.902 & 8.902 & 5.12 & 405.7 & 12 & AFM & [76] \\
\hline 75 & $\mathrm{CeMn}_{4} \mathrm{Al}_{8}$ & $\mathrm{ThMn}_{12}$ & 8.89 & 8.89 & 5.17 & 408.6 & 0 & PM & [76] \\
\hline 76 & $\mathrm{NdMn}_{4} \mathrm{Al}_{8}$ & $\mathrm{ThMn}_{12}$ & 8.925 & 8.925 & 5.133 & 408.9 & 7 & AFM & [76] \\
\hline 77 & $\mathrm{PrMn}_{4} \mathrm{Al}_{8}$ & $\mathrm{ThMn}_{12}$ & 8.962 & 8.962 & 5.143 & 413.1 & 11 & AFM & [76] \\
\hline 78 & $\mathrm{EuMn}_{4} \mathrm{Al}_{8}$ & $\mathrm{ThMn}_{12}$ & 8.982 & 8.982 & 5.161 & 416.4 & 20 & AFM & [76] \\
\hline 79 & $\mathrm{LaMn}_{4} \mathrm{Al}_{8}$ & $\mathrm{ThMn}_{12}$ & 9.031 & 9.031 & 5.166 & 421.3 & 0 & PM & [76] \\
\hline 80 & $\mathrm{ThMn}_{4} \mathrm{Al}_{8}$ & $\mathrm{ThMn}_{12}$ & 8.937 & 8.937 & 5.639 & 450.4 & 0 & PM & [80] \\
\hline 81 & $\mathrm{Mn}_{2} \mathrm{P}$ & $\mathrm{Fe}_{2} \mathrm{P}$ & 6.074 & 6.074 & 3.454 & 110.4 & 100 & AFM & $\begin{array}{l}{[81,} \\
82]\end{array}$ \\
\hline 82 & TiMnP & $\mathrm{Fe}_{2} \mathrm{P}$ & 6.188 & 6.188 & 3.451 & 114.4 & 0 & PM & [83] \\
\hline 83 & MnRhP & $\mathrm{Fe}_{2} \mathrm{P}$ & 6.226 & 6.226 & 3.581 & 120.2 & 401 & FM & [84] \\
\hline 84 & $\mathrm{Mn}_{2} \mathrm{As}$ & $\mathrm{Fe}_{2} \mathrm{P}$ & 6.3627 & 6.3627 & 3.6784 & 129.0 & 50 & AFM & [85] \\
\hline 85 & MnRuAs & $\mathrm{Fe}_{2} \mathrm{P}$ & 6.5155 & 6.5155 & 3.614 & 132.9 & 496 & FM & [84] \\
\hline 86 & MnRhAs & $\mathrm{Fe}_{2} \mathrm{P}$ & 6.482 & 6.482 & 3.714 & 135.1 & 190 & FM & [86] \\
\hline 87 & MnPdGe & $\mathrm{Fe}_{2} \mathrm{P}$ & 6.639 & 6.639 & 3.577 & 136.5 & 576 & FM & [87] \\
\hline 88 & MnPdAs & $\mathrm{Fe}_{2} \mathrm{P}$ & 6.626 & 6.626 & 3.756 & 142.8 & 210 & FM & [84] \\
\hline 89 & MnNiGe & $\mathrm{Ni}_{2} \mathrm{In}$ & 4.078 & 4.078 & 5.381 & 77.50 & 346 & AFM & [88] \\
\hline 90 & $\mathrm{MnPtAl}$ & $\mathrm{Ni}_{2} \mathrm{In}$ & 4.329 & 4.329 & 5.499 & 89.25 & 295 & AFM & [89] \\
\hline 91 & $\mathrm{MnPtGa}$ & $\mathrm{Ni}_{2} \mathrm{In}$ & 4.328 & 4.328 & 5.576 & 90.45 & 220 & FM & [90] \\
\hline 92 & $\mathrm{NiMnSb}$ & LiAlSi & 5.928 & 5.928 & 5.928 & 208.3 & 728 & FM & [91] \\
\hline 93 & MnIrAl & LiAlSi & 5.981 & 5.981 & 5.981 & 214.0 & 379 & FM & [92] \\
\hline 94 & $\mathrm{MnCuSb}$ & LiAlSi & 6.095 & 6.095 & 6.095 & 226.4 & 55 & AFM & [93] \\
\hline 95 & $\mathrm{MnRhSb}$ & LiAlSi & 6.142 & 6.142 & 6.142 & 231.7 & 320 & FM & [93] \\
\hline 96 & MnIrSn & LiAlSi & 6.182 & 6.182 & 6.182 & 236.3 & 265 & $\mathrm{FM}$ & [94] \\
\hline 97 & $\mathrm{MnPtSb}$ & LiAlSi & 6.21 & 6.21 & 6.21 & 239.5 & 585 & FM & [93] \\
\hline 98 & $\mathrm{PdMnSb}$ & LiAlSi & 6.231 & 6.231 & 6.231 & 241.9 & 500 & FM & [95] \\
\hline 99 & MnPdTe & LiAlSi & 6.2605 & 6.2605 & 6.2605 & 245.4 & 17 & AFM & [96] \\
\hline 100 & $\mathrm{MnPtSn}$ & LiAlSi & 6.264 & 6.264 & 6.264 & 245.8 & 330 & FM & [93] \\
\hline 101 & MnAuSn & LiAlSi & 6.4313 & 6.4312 & 6.4312 & 266.0 & 740 & $\mathrm{FM}$ & [97] \\
\hline 102 & $\mathrm{MnRhSi}$ & TiNiSi & 6.1994 & 3.7968 & 7.1387 & 168.0 & 367 & AFM & [98] \\
\hline 103 & HfMnP & TiNiSi & 6.3257 & 3.6298 & 7.409 & 170.1 & 320 & $\mathrm{FM}$ & [99] \\
\hline 104 & $\mathrm{ZrMnP}$ & TiNiSi & 6.41 & 3.657 & 7.515 & 176.2 & 370 & $\mathrm{FM}$ & [99] \\
\hline 105 & LuMnSi & TiNiSi & 6.82 & 3.962 & 7.839 & 211.8 & 255 & AFM & [100] \\
\hline 106 & UMnGe & TiNiSi & 6.866 & 4.2594 & 7.3618 & 215.3 & 240 & AFM & [101] \\
\hline 107 & TbMnGe & TiNiSi & 7.077 & 4.132 & 8.166 & 238.8 & 510 & AFM & [102] \\
\hline 108 & GdMnGe & TiNiSi & 7.138 & 4.1698 & 8.191 & 243.8 & 490 & AFM & [103] \\
\hline 109 & $\mathrm{MnNi}$ & $\mathrm{AuCu}$ & 3.69 & 3.69 & 2.609 & 35.52 & 1070 & AFM & [104] \\
\hline 110 & $\mathrm{MnPt}$ & $\mathrm{AuCu}$ & 3.855 & 3.855 & 2.726 & 40.51 & 970 & AFM & [104] \\
\hline 111 & $\mathrm{MnGa}$ & $\mathrm{AuCu}$ & 3.889 & 3.889 & 2.75 & 41.59 & 629 & FM & [105] \\
\hline 112 & MnRh & $\mathrm{AuCu}$ & 3.93 & 3.93 & 2.779 & 42.92 & 0 & PM & [104] \\
\hline 113 & $\mathrm{MnPd}$ & $\mathrm{AuCu}$ & 4.069 & 4.069 & 2.877 & 47.63 & 780 & AFM & [104] \\
\hline 114 & $\mathrm{MnAl}$ & $\mathrm{AuCu}$ & 3.9 & 3.9 & 3.54 & 53.84 & 578 & $\mathrm{FM}$ & [106] \\
\hline 115 & $\mathrm{MnRh}_{2} \mathrm{Sb}$ & $\mathrm{AuCu}$ & 4.171 & 4.171 & 3.494 & 60.79 & 304 & $\mathrm{FM}$ & [107] \\
\hline 116 & $\mathrm{MnAlGe}$ & $\mathrm{Cu}_{2} \mathrm{Sb}$ & 3.914 & 3.914 & 5.933 & 90.89 & 518 & $\mathrm{FM}$ & [108] \\
\hline 117 & MnGaGe & $\mathrm{Cu}_{2} \mathrm{Sb}$ & 3.966 & 3.966 & 5.885 & 92.57 & 440 & FM & [109] \\
\hline 118 & $\mathrm{MnZnSb}$ & $\mathrm{Cu}_{2} \mathrm{Sb}$ & 4.173 & 4.173 & 6.233 & 108.5 & 310 & FM & [110] \\
\hline 119 & LiMnAs & $\mathrm{Cu}_{2} \mathrm{Sb}$ & 4.267 & 4.267 & 6.178 & 112.5 & 374 & AFM & [111] \\
\hline 120 & YMnSi & $\mathrm{Cu}_{2} \mathrm{Sb}$ & 3.978 & 3.978 & 7.152 & 113.2 & 282 & $\mathrm{FM}$ & [112] \\
\hline 121 & GdMnSi & $\mathrm{Cu}_{2} \mathrm{Sb}$ & 4.009 & 4.009 & 7.183 & 115.5 & 314 & FM & [113] \\
\hline 122 & NdMnSi & $\mathrm{Cu}_{2} \mathrm{Sb}$ & 4.087 & 4.087 & 7.245 & 121.0 & 175 & AFM & [114] \\
\hline 123 & CeMnSi & $\mathrm{Cu}_{2} \mathrm{Sb}$ & 4.13 & 4.13 & 7.279 & 124.2 & 240 & AFM & [114] \\
\hline 124 & CaMnSi & $\mathrm{Cu}_{2} \mathrm{Sb}$ & 4.1814 & 4.1814 & 7.1429 & 124.9 & 360 & AFM & [115] \\
\hline
\end{tabular}


Table 4. Cont.

\begin{tabular}{lccccccccc}
\hline No. & Compound & $\begin{array}{c}\text { Structure } \\
\text { Type }\end{array}$ & $\boldsymbol{a}(\AA)$ & $\boldsymbol{b}(\AA)$ & $\boldsymbol{c}(\AA)$ & $\boldsymbol{V}\left(\mathbf{\AA}^{3}\right)$ & $\begin{array}{c}\boldsymbol{T}_{\text {order }} \\
(\mathbf{K})\end{array}$ & Type & Ref. \\
\hline 125 & $\mathrm{PrMnGe}$ & $\mathrm{Cu}_{2} \mathrm{Sb}$ & 4.196 & 4.196 & 7.344 & 129.3 & 415 & AFM & {$[116]$} \\
126 & $\mathrm{LaMnSi}$ & $\mathrm{Cu}_{2} \mathrm{Sb}$ & 4.189 & 4.189 & 7.378 & 129.5 & 310 & AFM & {$[114]$} \\
127 & $\mathrm{CaMnGe}$ & $\mathrm{Cu}_{2} \mathrm{Sb}$ & 4.23 & 4.23 & 7.27 & 130.1 & 420 & AFM & {$[115]$} \\
128 & $\mathrm{CeMnGe}$ & $\mathrm{Cu}_{2} \mathrm{Sb}$ & 4.226 & 4.226 & 7.386 & 131.9 & 415 & AFM & {$[116]$} \\
129 & $\mathrm{LaMnGe}$ & $\mathrm{Cu}_{2} \mathrm{Sb}$ & 4.277 & 4.277 & 7.449 & 136.3 & 420 & AFM & {$[116]$} \\
130 & $\mathrm{SrMnGe}$ & $\mathrm{Cu}_{2} \mathrm{Sb}$ & 4.4 & 4.4 & 7.52 & 145.6 & 254 & AFM & {$[117]$} \\
131 & $\mathrm{CaMnSn}$ & $\mathrm{Cu}_{2} \mathrm{Sb}$ & 4.4839 & 4.4839 & 7.4988 & 150.8 & 250 & AFM & {$[117]$} \\
132 & $\mathrm{BaMnGe}$ & $\mathrm{Cu}_{2} \mathrm{Sb}$ & 4.5 & 4.5 & 7.92 & 160.4 & 425 & AFM & {$[117]$} \\
133 & $\mathrm{SrMnSn}$ & $\mathrm{Cu}_{2} \mathrm{Sb}$ & 4.662 & 4.662 & 7.749 & 168.4 & 252 & AFM & {$[117]$} \\
\hline
\end{tabular}
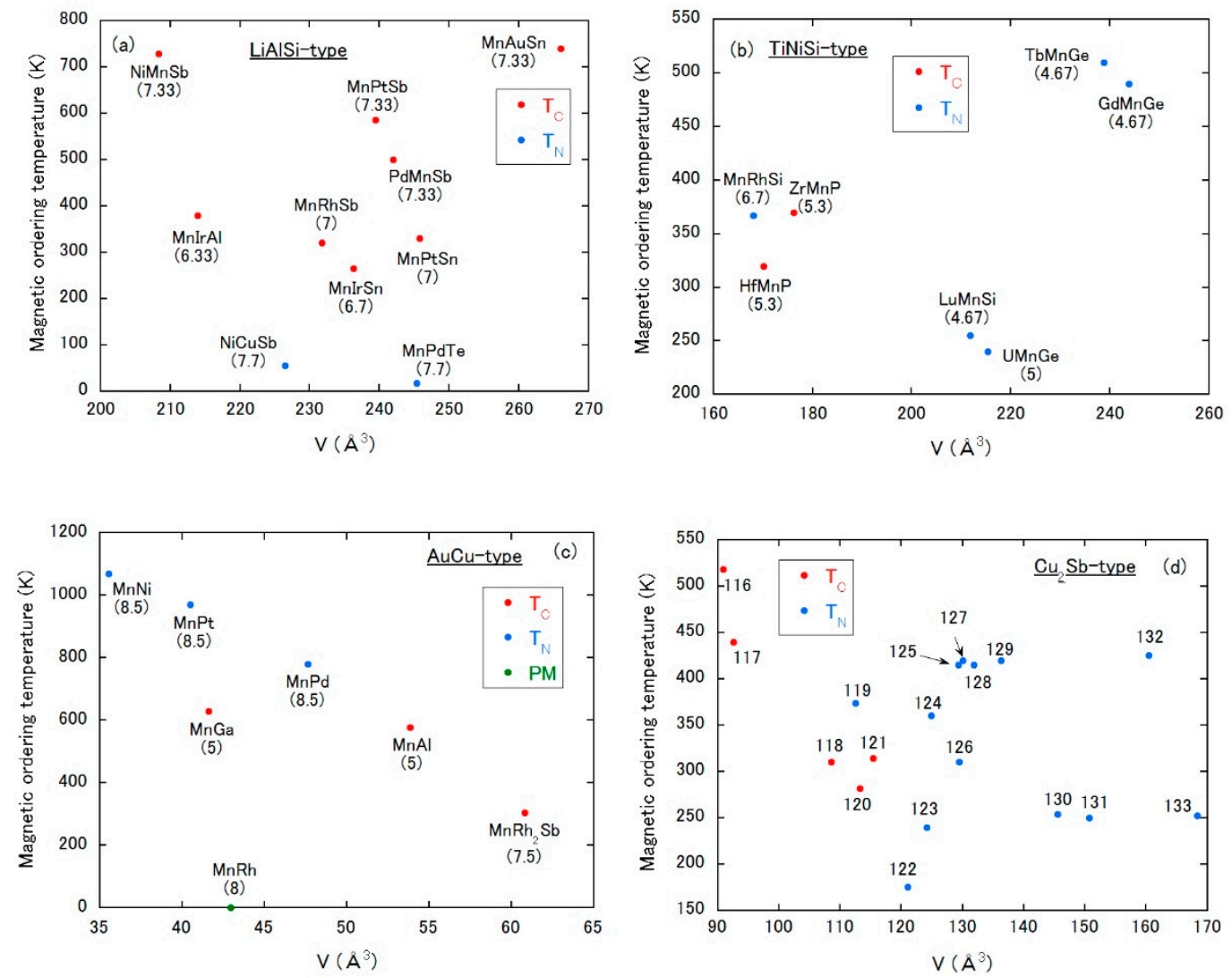

Figure 13. Magnetic ordering temperature vs. unit cell volume plot of Mn-based compounds with (a) LiAlSi-type, (b) TiNiSi-type, (c) AuCu-type and (d) $\mathrm{Cu}_{2}$ Sb-type, respectively. PM means a paramagnetic state down to low temperatures. In $(\mathbf{a}-\mathbf{c})$, valence electron count per atom (VEC) is denoted under each chemical formula. The numbers in (d) correspond to those in Table 4.

\subsubsection{TiNiSi-Type Structure}

This is the famous orthorhombic structure with the space group Pnma (No. 62). Mn atoms occupy the $4 c$ site. As shown in Figure 13b, the border between AFM and FM states may be situated at $V=180-200 \AA^{3}$. Moreover, only the compounds accompanied by VEC $=5.3$ show the FM ground state. The interstitial alloying with the change in VEC might be effective for a magnetic state change.

\subsubsection{AuCu-Type Structure}

The AuCu-type structure is tetragonal with the space group of $P 4 / m m m$ (No. 123). Except for $\mathrm{MnRh}_{2} \mathrm{Sb}, \mathrm{Mn}$ atoms occupy two crystallographic sites called the $1 a$ and $1 c$ sites. In $\mathrm{MnRh}_{2} \mathrm{Sb}, \mathrm{Mn}$ sites 
are reduced to the $1 a$ one. As in the LiAlSi-type structure, the magnetic ordering type would be correlated with VEC; the AFM or paramagnetic state is observed for a VEC larger than 8, and the FM state for VEC $=5$ or 7.5. Under a fixed VEC value, $T_{N}$ systematically decreases with increasing volume, while the volume dependence of $T_{C}$ is very weak for ferromagnets.

\subsection{8. $\mathrm{Cu}_{2} \mathrm{Sb}$-Type Structure}

This is the tetragonal structure (P4/nmm, No. 129), in which Mn atoms occupy the $2 a$ site. Contrary to the prediction of the Bethe-Slater curve, a volume expansion favors an AFM state. The magnitude of the magnetic ordering temperature is likely suppressed by expanding the volume.

\section{Rare-Earth-Based Compounds}

\section{1. $R_{5} \mathrm{Si}_{3} B_{x}$}

The $\mathrm{Mn}_{5} \mathrm{Si}_{3}$-type $\mathrm{R}_{5} \mathrm{Si}_{3}$ allows for interstitial boron atoms, which leads to volume reduction with an increasing boron concentration [118]. For the parent compound with $\mathrm{x}=0$, the AFM orderings are observed in $\mathrm{R}=\mathrm{Gd}$ and $\mathrm{Tb}$ at $T_{\mathrm{N}}=75$ and $69 \mathrm{~K}$, respectively. On the other hand, $\mathrm{R}=\mathrm{Dy}$ and Ho show the FM orderings at $T_{\mathrm{C}}=120$ and $11 \mathrm{~K}$, respectively. By adding boron atoms, the $T_{\mathrm{N}}$ of $\mathrm{R}=\mathrm{Gd}$ and $\mathrm{Tb}$ are slightly reduced to $67 \mathrm{~K}$ in both cases, and the changes of $T_{C}$ in $\mathrm{R}=\mathrm{Dy}$ and Ho are also subtle; $T_{C}$ remains at $120 \mathrm{~K}$ in $R=$ Dy and is slightly enhanced to $15 \mathrm{~K}$ in $R=$ Ho. In each compound, $\mu_{\text {eff }}$ does not so largely depend on the boron addition, which means a weak hybridization between rare earth and boron atoms.

\section{2. $\mathrm{NdScSiC}_{x}$}

This compound crystallizes into the tetragonal $\mathrm{La}_{2} \mathrm{Sb}$-type structure (I4/mmm, No. 139) [119]. The interstitial carbon atoms expand the $a$ axis and contract the $c$ axis. The latter fact, in particular, enhances the chemical bonding between $\mathrm{Nd}$ and $\mathrm{C}$ and decreases $T_{\mathrm{C}}=171 \mathrm{~K}$ in the parent NdScSi to $50 \mathrm{~K}$ at $\mathrm{x}=0.5$. Taking into account that the $4 f$ orbital of a rare-earth atom is usually well localized, the drastic change in magnetic ordering temperature is unexpected as in $\mathrm{R}_{5} \mathrm{Si}_{3} \mathrm{~B}_{\mathrm{x}}$. Thus, the large modification of $T_{\mathrm{C}}$ in this compound is very interesting.

\section{Perspectives}

\subsection{Application of Mn-Based Magnetic Materials}

The change in magnetism between FM and AFM states or the additional formation of new magnetic coupling at rather high temperatures by interstitial atoms is substantially valuable in a magnetic device integrated with both FM and AFM materials due to the easy on-demand control of magnetism in the fabrication process. At the present stage, Mn-based compounds fulfill the requirement of change or the additional formation of magnetism, while in Fe-based compounds, only improvements of FM properties are extensively investigated and the change (or the additional formation) of the magnetic state is not well explored. Focusing on the research area of the permanent magnet, a rare-earth Mn-based permanent magnet is still missing, although the MnBi-type magnets are well known. Based on the Bethe-Slater curve, Mn atoms favor the FM state with expanding $\mathrm{Mn}-\mathrm{Mn}$ distance. Therefore, the density of Mn could not be so increased as in rare-earth Fe-based permanent magnets, resulting in a smaller saturation magnetization. However, there exists a large gap of $\mathrm{BH}$ energy product between the $\mathrm{NdFeB}$ magnets and ferrite magnets, and a rare-earth $\mathrm{Mn}$-based permanent magnet may be a good candidate filling the gap [120].

\subsection{Towards Further on-Demand Control of Magnetism}

Further improvement of magnetic properties in the on-demand control would be achieved by another strategy such as a composition effect and carrier doping. If a metallurgical phase diagram of 
a target compound possesses a homogeneity range, the magnetic ordering temperature often varies with the atomic composition. For example, the $T_{C}$ of $\mathrm{Tb}_{2} \mathrm{Co}_{2} \mathrm{Ga}$ ranges rather widely from 75 to $145 \mathrm{~K}$ by changing the starting composition [121]. Such a composition effect is reported in other compounds [122-124] such as $\mathrm{Nd}_{3} \mathrm{Pd}_{20} \mathrm{Ge}_{6}, \mathrm{~Tb}_{3} \mathrm{Co}_{3} \mathrm{Ga}$ and $\mathrm{Mn}_{1+x} \mathrm{Ga}$. In many cases, the crystal structure parameters slightly change, which heavily affects the magnetic exchange interactions.

The magnetic anisotropy energy is one of the important factors in characterizing a ferromagnet. It is known that it can be tuned by doping, mainly due to the variation of the density of states near the Fermi level. The doping effect is reported in, for example, $\mathrm{Ni}_{2} \mathrm{MnGa}, \mathrm{SmCo}_{5-\mathrm{x}} \mathrm{Fe}_{1} \mathrm{MnBi}_{1} \mathrm{Nd}_{2} \mathrm{Fe}_{17} \mathrm{X}$ $(\mathrm{X}=\mathrm{C}$ or $\mathrm{N}), \mathrm{Ce}_{2} \mathrm{AuP}_{3}$ and so on [125-129]. Taking into account the crystal symmetry, which is related to the magnetic anisotropy energy, a lower crystal symmetry with more tunable crystal parameters might be favorable.

\subsection{Comments on Control of Magnetism by External Field}

Another interesting control of magnetism is the manipulation of spin by external fields such as the electric field and the optical light. For example, the employment of an electric double-layer transistor has achieved a control of magnetism by weak voltage [130]. Recently, an optical change in magnetism through the Kondo effect has been reported [131]. The interstitial atoms may precisely control the magnetism so that only a small magnitude of external field is required for the device working, and the power consumption can be highly reduced.

\subsection{Comments on Critical Behavior}

From the fundamental viewpoint, research into critical behavior is interesting. Actually, in strongly correlated electron systems, there have been plenty of studies for seeking a quantum critical point under the suppression of magnetism [132-136]. We speculate that a formation of FM exchange coupling above room temperature would be a discontinuous phenomenon as mentioned in the results of Mn-based compounds. While it is not well investigated for rare-earth Fe-based compounds, we note that $\mathrm{RFe}_{11} \mathrm{TiC}_{\mathrm{x}}$ and $\mathrm{RFe}_{11} \mathrm{TiC}_{\mathrm{x}}$ show a finite change in $T_{\mathrm{C}}$ at an infinitely zero value of volume expansion depending on $\mathrm{R}$ species [137].

\section{Summary}

This review surveyed the studies of interstitial atoms in rare-earth Fe-, Mn-, rare-earth-based magnetic materials, especially focusing on the Mn-based compounds since the effect of interstitial atoms is not well investigated. The light elements would occupy the interstitial sites in the respective crystal structure, and change the unit cell volume, although the degree of change depends on the strength of orbital hybridization between the magnetic and interstitial atoms. The light elements are occasionally essential for the stabilization of the desired crystal structure. In the abundant studies of rare-earth Fe-based permanent magnets, the role of interstitial atoms seems to be restricted to the enhancements of $T_{C}$ and saturated magnetization, and the change in easy magnetization direction. In several Mn-based compounds, magnetic ordering temperature and the magnetization also tends to be increased with the increasing density of interstitial atoms after the appearance of FM states. However, it is peculiar for the Mn-based compounds that the change or additional formation of magnetism by interstitial atoms is possible: the change from the AFM (paramagnetic) to FM state or the additional formation of the FM state coexisting with the ground state of Mn atoms in the parent compound. Furthermore, the FM exchange coupling would abruptly emerge under a slight addition of interstitial elements, and this is an important research topic for a deep understanding of interstitial atom engineering. The candidates of Mn-based compounds, possibly showing the change in magnetism by interstitial atoms, are briefly discussed. We note that not only the unit cell volume but also the VEC should be taken into account to design the change in magnetism. The change between AFM and FM states by just controlling the number of interstitial atoms is a very promising elemental technology for making highly functional magnetic devices integrated with both FM and AFM materials without a large lattice mismatch. 
Author Contributions: Conceptualization, J.K., N.S. and M.T.; methodology, J.K., N.S. and M.T.; formal analysis, J.K., K.S., T.H. and F.H.; writing-original draft preparation, J.K.; writing-review and editing, J.K., N.S. and M.T. All authors have read and agreed to the published version of the manuscript.

Funding: This research received no external funding.

Acknowledgments: J.K. is grateful for the support provided by Comprehensive Research Organization of Fukuoka Institute of Technology.

Conflicts of Interest: The authors declare no conflict of interest.

\section{References}

1. Goldschmidt, H.J. Interstitial Alloys; Butterworths: London, UK, 1967.

2. Grandjean, F.; Long, G.J.; Buschow, K.H.J. Interstitial Intermetallic Alloys; Kluwer Academic Publishers: Dordrecht, The Netherlands, 1995.

3. Yang, Y.; Yang, J.; Han, J.; Wang, C.; Liu, S.; Du, H. Researh and Development of Interstitial Compounds. IEEE Trans. Magn. 2015, 51, 2103806. [CrossRef]

4. Nieves, P.; Arapan, S.; Maudes-Raedo, J.; Marticorena-Sánchez, R.; Del Brío, N.L.; Kovacs, A.; Echevarria-Bonet, C.; Salazar, D.; Weischenberg, J.; Zhang, H.; et al. Database of novel magnetic materials for high-performance permanent magnet development. Comput. Mater. Sci. 2019, 168, 188-202. [CrossRef]

5. Coey, J.M.D. Perspective and Prospects for Rare Earth Permanent Magnets. Engineering 2020, 6, 119-131. [CrossRef]

6. Hadjipanayis, G.C.; Gabay, A.M.; Schönhöbel, A.M.; Martín-Cid, A.; Barandiaran, J.M.; Niarchos, D. $\mathrm{ThMn}_{12}$-Type Alloys for Permanent Magnets. Engineering 2020, 6, 141-147. [CrossRef]

7. Slater, J.C. Cohesion in Monovalent Metals. Phys. Rev. 1930, 35, 509-529. [CrossRef]

8. Slater, J.C. Atomic Shielding Constants. Phys. Rev. 1930, 36, 57-64. [CrossRef]

9. Sommerfeld, A.; Bethe, H. Handbuch der Physik; Springer: Berlin, Germany, 1933; Volume 24, p. 595.

10. Cardias, R.; Szilva, A.; Bergman, A.; Marco, I.D.; Katsnelson, M.I.; Lichtenstein, A.I.; Nordström, L.; Klautau, A.B.; Eriksson, O.; Kvashnin, Y.O. The Bethe-Slater curve revisited; new insights from electronic structure theory. Sci. Rep. 2017, 7, 4058. [CrossRef]

11. Givord, D.; Lemaire, R. Magnetic Transition and Anomalous Thermal Expansion in $\mathrm{R}_{2} \mathrm{Fe}_{17}$ Compounds. IEEE Trans. Magn. 1970, MAG-10, 109-113.

12. Palstra, T.T.M.; Nieuwenhuys, G.J.; Mydosh, J.A.; Buschow, K.H.J. Mictomagnetic, ferromagnetic, and antiferromagnetic transitions in $\mathrm{La}\left(\mathrm{Fe}_{\mathrm{x}} \mathrm{Al}_{1-\mathrm{x}}\right)_{13}$ intermetallic compounds. Phys. Rev. B 1985, 31, 4622-4632. [CrossRef]

13. Kitagawa, J.; Yakabe, G.; Nakayama, A.; Nishizaki, T.; Tsubota, M. Competition between ferromagnetic and antiferromagnetic states in $\mathrm{Al}_{8.5-\mathrm{x}} \mathrm{Fe}_{23} \mathrm{Ge}_{12.5+\mathrm{x}}(0 \leq \mathrm{x} \leq 3)$. J. Solid State Chem. 2020, 284, 121188. [CrossRef]

14. Chen, D.; Gondō, Y. Temperature Dependence of the Magneto-Optic Effect and Resonance Phenomena in Oriented MnBi Films. J. Appl. Phys. 1964, 35, 1024-1025. [CrossRef]

15. Park, J.H.; Hong, Y.K.; Bae, S.; Lee, J.J.; Jalli, J.; Abo, G.S.; Neveu, N.; Kim, S.G.; Choi, C.J.; Lee, J.G. Saturation magnetization and crystalline anisotropy calculations for MnAl permanent magnet. J. Appl. Phys. 2010, 107, 09A731. [CrossRef]

16. Gabay, A.M.; Hadjipanayis, G.C.; Cui, J. New anisotropic MnBi permanent magnets by field-annealing of compacted melt-spun alloys modified with Mg and Sb. J. Magn. Magn. Mater. 2020, 495, 165860. [CrossRef]

17. Xiang, Z.; Xu, C.; Wang, T.; Song, Y.; Yang, H.; Lu, W. Enhanced magnetization and energy product in isotropic nanocrystalline $\mathrm{Mn}_{55} \mathrm{Al}_{45}$ alloys with boron doping. Intermetallics 2018, 101, 13-17. [CrossRef]

18. Zhao, S.; Wu, Y.; Zhang, C.; Wang, J.; Fu, Z.; Zhang, R.; Jiang, C. Stabilization of $\tau$-phase in carbon-doped MnAl magnetic alloys. J. Alloy. Compd. 2018, 755, 257-264. [CrossRef]

19. Jonietz, F.; Mühlbauer, S.; Pfleiderer, C.; Neubauer, A.; Münzer, W.; Bauer, A.; Adams, T.; Georgii, R.; Böni, P.; Duine, R.A.; et al. Spin Transfer Torques in MnSi at Ultralow Current Densities. Science 2010, 330, 1648-1651. [CrossRef]

20. Nakatsuji, S.; Kiyohara, N.; Higo, T. Large anomalous Hall effect in a non-collinear antiferromagnet at room temperature. Nature 2015, 527, 212-215. [CrossRef]

21. Sun, H.; Coey, J.M.D.; Otani, Y.; Hurley, D.P.F. Magnetic properties of a new series of rare-earth iron nitrides: $\mathrm{R}_{2} \mathrm{Fe}_{17} \mathrm{~N}_{\mathrm{y}}$ (y approximately 2.6). J. Phys. Condens. Matter 1990, 2, 6465-6470. [CrossRef] 
22. Mukai, T.; Fujimoto, T. Kerr microscopy observation of nitrogenated $\mathrm{Sm}_{2} \mathrm{Fe}_{17}$ intermetallic compounds. J. Magn. Magn. Mater. 1992, 103, 165-173. [CrossRef]

23. Coey, J.M.D. Novel Permanent Magnetic Materials. Phys. Scr. 1991, T39, 21-28. [CrossRef]

24. Wei, Y.-N.; Sun, K.; Fen, Y.-B.; Zhang, J.-X.; Hu, B.-P.; Wang, Y.-Z.; Rao, X.-L.; Liu, G.-C. Structural and intrinsic magnetic properties of $\mathrm{Sm}_{2} \mathrm{Fe}_{17} \mathrm{~N}_{\mathrm{y}}(\mathrm{y}=2-8)$. J. Alloy. Compd. 1993, 194, 9-12. [CrossRef]

25. Coey, J.M.D.; Hurley, D.P.F. New interstitial rare-earth iron intermetallics produced by gas phase reaction. J. Magn. Magn. Mater. 1992, 104-107, 1098-1101. [CrossRef]

26. Christodoulou, C.N.; Takeshita, T. Interstitial carbonation of the $\mathrm{Sm}_{2} \mathrm{Fe}_{17}$ phase by reaction with hydrocarbons. J. Alloy. Compd. 1992, 190, 41-48. [CrossRef]

27. Coey, J.M.D.; Otani, Y. Magnetic properties of $\mathrm{R}_{2} \mathrm{Fe}_{17} \mathrm{~N}_{3-\delta}$. J. Magn. Soc. Jpn. 1991, 15, 677-684.

28. Li, H.-S.; Coey, J.M.D. Magnetic Properties of Ternary Rare-Earth Transition-Metal Compounds. In Handbook of Magnetic Materials VI; Buschow, K.H.J., Ed.; Elsevier: Amsterdam, The Netherlands, 1991.

29. Coey, J.M.D.; Sun, H.; Hurley, D.P.F. Intrinsic magnetic properties of new rare-earth iron intermetallic series. J. Magn. Magn. Mater. 1991, 101, 310-316. [CrossRef]

30. Harashima, Y.; Terakura, K.; Kino, H.; Ishibashi, S.; Miyake, T. First-Principles Study of Structural and Magnetic Properties of $\mathrm{R}(\mathrm{Fe}, \mathrm{Ti})_{12}$ and $\mathrm{R}(\mathrm{Fe}, \mathrm{Ti}){ }_{12} \mathrm{~N}(\mathrm{R}=\mathrm{Nd}, \mathrm{Sm}, \mathrm{Y})$. JPS Conf. Proc. 2015, 5, 011021.

31. Kong, L.-S.; Cao, L.; Shen, B.-G. Structures and magnetic properties of the nitrides $\left(\mathrm{Nd}_{1-\mathrm{x}} \mathrm{Dy}_{\mathrm{x}}\right) \operatorname{TiFe}_{11} \mathrm{~N}_{\mathrm{y}}$. J. Magn. Magn. Mater. 1993, 124, 301-304. [CrossRef]

32. Hirayama, Y.; Miyake, T.; Hono, K. Potential and issues of permanent magnet candidate compound $\mathrm{Nd}(\mathrm{FeM})_{12} \mathrm{~N}$ with $\mathrm{ThMn}_{12}$-type structure. Mater. Jpn. 2016, 55, 97-103. [CrossRef]

33. Yang, Y.-C.; Zhang, X.-D.; Kong, L.-S.; Pan, Q. Magnetocrystalline anisotropies of $\mathrm{RTiFe}_{11} \mathrm{~N}_{\mathrm{x}}$ compounds. Appl. Phys. Lett. 1991, 58, 2042-2044. [CrossRef]

34. Chang, H.; Zhang, X.; Yang, Y. A study on the effect of hydrogen in the compounds with BaCd $\mathrm{B}_{11}$-type structure. Solid State Commun. 2001, 119, 403-407. [CrossRef]

35. Miyake, T.; Terakura, K.; Harashima, Y.; Kino, H.; Ishibashi, S. First-Principles Study of Magnetocrystalline Anisotropy and Magnetization in $\mathrm{NdFe}_{12}, \mathrm{NdFe}_{11} \mathrm{Ti}$, and $\mathrm{NdFe}_{11} \mathrm{TiN}$. J. Phys. Soc. Jpn. 2014, 83, 043702. [CrossRef]

36. Harashima, Y.; Terakura, K.; Kino, H.; Ishibashi, S.; Miyake, T. First-principles study on stability and magnetism of $\mathrm{NdFe}_{11} \mathrm{M}$ and $\mathrm{NdFe}_{11} \mathrm{MN}$ for $\mathrm{M}=\mathrm{Ti}, \mathrm{V}, \mathrm{Cr}, \mathrm{Mn}, \mathrm{Fe}, \mathrm{Co}, \mathrm{Ni}, \mathrm{Cu}, \mathrm{Zn}$. J. Appl. Phys. 2016, 120, 203904. [CrossRef]

37. Fukazawa, T.; Akai, H.; Harashima, Y.; Miyake, T. First-principles study of intersite magnetic couplings in $\mathrm{NdFe}_{12}$ and $\mathrm{NdFe}_{12} \mathrm{X}(\mathrm{X}=\mathrm{B}, \mathrm{C}, \mathrm{N}, \mathrm{O}, \mathrm{F})$. J. Appl. Phys. 2017, 122, 053901. [CrossRef]

38. Sato, T.; Ohsuna, T.; Yano, M.; Kato, A.; Kaneko, Y. Permanent magnetic properties of $\mathrm{NdFe}_{12} \mathrm{~N}_{\mathrm{x}}$ sputtered films epitaxially grown on V buffer layer. J. Appl. Phys. 2017, 122, 053903. [CrossRef]

39. Sepehri-Amina, H.; Tamazawa, Y.; Kambayashi, M.; Saito, G.; Takahashi, Y.K.; Ogawa, D.; Ohkubo, T.; Hirosawa, S.; Doi, M.; Shima, T.; et al. Achievement of high coercivity in $\mathrm{Sm}\left(\mathrm{Fe}_{0.8} \mathrm{Co}_{0.2}\right)_{12}$ anisotropic magnetic thin film by boron doping. Acta Mater. 2020, 194, 337-342. [CrossRef]

40. Mao, W.; Zhang, X.; Ji, C.; Chang, H.; Cheng, B.; Yang, Y.; Du, H.; Xue, Y.; Zhang, B.; Wang, L.; et al. Structural and magnetic properties of $\operatorname{PrFe}_{12-x} \mathrm{~V}_{\mathrm{x}}$ and their nitrides. Acta Mater. 2001, 49, 721-728. [CrossRef]

41. Buschow, K.H.J.; Sherwood, R.C. Magnetic properties and hydrogen absorption in rare-earth intermetallics of the type $\mathrm{RMn}_{2}$ and $\mathrm{R}_{6} \mathrm{Mn}_{23}$. J. Appl. Phys. 1977, 48, 4643-4648. [CrossRef]

42. Shiga, M. Magnetism and spin fluctuations of laves phase manganese compounds. Phys. B + C 1988, 149, 293-305. [CrossRef]

43. Corbett, J.D.; Garcia, E.; Guloy, A.M.; Hurng, W.-M.; Kwon, Y.-U.; Leon-Escamilla, E.A. Widespread Interstitial Chemistry of $\mathrm{Mn}_{5} \mathrm{Si}_{3}$-Type and Related Phases. Hidden Impurities and Opportunities. Chem. Mater. 1998, 10, 2824-2836. [CrossRef]

44. Gajdzik, M.; Sürgers, C.; Kelemen, M.; Löhneysen, H.v. Ferromagnetism in carbon-doped $\mathrm{Mn}_{5} \mathrm{Si}_{3}$ films. J. Appl. Phys. 2000, 87, 6013-6015. [CrossRef]

45. Sürgers, C.; Gajdzik, M.; Fischer, G.; Löhneysen, H.V.; Welter, E.; Attenkofer, K. Preparation and structural characterization of ferromagnetic $\mathrm{Mn}_{5} \mathrm{Si}_{3} \mathrm{C}_{\mathrm{x}}$ films. Phys. Rev. B 2003, 68, 174423. [CrossRef]

46. Saha, D.K.; Ohshima, K.; Wey, M.Y.; Miida, R.; Kimoto, T. Structure and magnetism of fcc Pd-Mn alloys. Phys. Rev. B 1994, 49, 15715-15722. [CrossRef] [PubMed] 
47. Rashid, M.H.; Sellmyer, D.J. Spin-glass-like freezing in disordered $\mathrm{MnPd}_{3}$ and $\mathrm{CrPd}_{3}$ alloys. J. Appl. Phys. 1984, 55, 1735-1737. [CrossRef]

48. Sakamoto, Y.; Takao, K.; Nagaoka, Y.; Kida, H.; Flanagan, T.B. Investigations of ordered structures in boron-containing $\mathrm{Pd}_{3} \mathrm{Mn}$ alloys. J. Alloy. Compd. 1993, 197, 35-41. [CrossRef]

49. Kitagawa, J.; Sakaguchi, K. New room-temperature ferromagnet: B-added $\mathrm{Pd}_{0.75} \mathrm{Mn}_{0.25}$ alloy. J. Magn. Magn. Mater. 2018, 468, 115-122. [CrossRef]

50. Worsham, J.E., Jr.; Wilkinson, M.K.; Shull, C.G. Neutron-diffraction observations on the palladium-hydrogen and palladium-deuterium systems. J. Phys. Chem. Solids 1957, 3, 303-310. [CrossRef]

51. Kitagawa, J.; Hara, T.; Sakaguchi, K.; Shirakawa, N.; Tsubota, M. Emergence of room-temperature ferromagnetism in boron-added Mn compounds. In Proceedings of the Joint European Magnetic Symposia 2019, Uppsala, Sweden, 26-30 August 2019; p. 158.

52. Izumi, F.; Momma, K. Three-dimensional visualization in powder diffraction. Solid State Phenom. 2007, 130, 15-20. [CrossRef]

53. Kotur, B.Y.; Palasyuk, A.M.; Bauer, E.; Michor, H.; Hilscher, G. Uncommon conductivity of R-Mn-Al (R = Gd, $\mathrm{Tb}$ ) ternary compounds. J. Phys. Condens. Matter 2001, 13, 9421-9431. [CrossRef]

54. Graf, T.; Felser, C.; Parkin, S.S.P. Simple rules for the understanding of Heusler compounds. Prog. Solid State Chem. 2011, 39, 1-50. [CrossRef]

55. Sen, S.; Singh, C.; Mukharjee, P.K.; Nath, R.; Nayak, A.K. Observation of the topological Hall effect and signature of room-temperature antiskyrmions in Mn-Ni-Ga $D_{2 d}$ Heusler magnets. Phys. Rev. B 2019, 99, 134404. [CrossRef]

56. Devi, P.; Zavareh, M.G.; Mejía, C.S.; Hofmann, K.; Albert, B.; Felser, C.; Nicklas, M.; Singh, S. Reversible adiabatic temperature change in the shape memory Heusler alloy Ni2.2Mn0.8Ga: An effect of structural compatibility. Phys. Rev. Mater. 2018, 2, 122401. [CrossRef]

57. Lemoine, P.; Vernière, A.; Mazet, T.; Malaman, B. Magnetic and magnetocaloric properties of $R_{6} M_{23}(R=Y$, Nd, Sm, Gd-Tm, Lu) compounds. J. Magn. Magn. Mater. 2011, 323, 2690-2695. [CrossRef]

58. Tsvyashchenko, A.V.; Popova, S.V.; Makhotkin, V.E.; Fradkov, V.A.; Zaritskii, V.N. Investigations of the magnetic properties of the $\mathrm{Yb}_{6} \mathrm{Mn}_{23}$ intermetallic compound. J. Less-Common Met. 1984, 96, 99-102. [CrossRef]

59. Malik, S.K.; Takeshita, T.; Wallace, W.E. Hydrogen induced magnetic ordering in $\mathrm{Th}_{6} \mathrm{Mn}_{23}$. Solid State Commun. 1977, 23, 599-602. [CrossRef]

60. Bushow, K.H.J. Magnetic properties of the ternary hydrides of $\mathrm{Nd}_{6} \mathrm{Mn}_{23}$ and $\mathrm{Sm}_{6} \mathrm{Mn}_{23}$. Solid State Commun. 1981, 40, 207-210. [CrossRef]

61. Hardman-Rhyne, K.; Rhyne, J.J.; Prince, E.; Crowder, C.; James, W.J. Magnetic and crystallographic structure of $\mathrm{Y}_{6} \mathrm{Mn}_{23} \mathrm{D}_{23}$. Phys. Rev. B 1984, 29, 416-422. [CrossRef]

62. Hardman-Rhyne, K.; Kevin Smith, H.; Wallace, W.E. Magnetic and crystallographic structure of $\operatorname{Th}_{6} \mathrm{Mn}_{23} \mathrm{D}_{\mathrm{x}}$. J. Less-Common Met. 1984, 96, 201-211. [CrossRef]

63. Pourarian, F.; Boltich, E.B.; Wallace, W.E.; Craig, R.S.; Malik, S.K. Magnetic characteristics of $\mathrm{R}_{6} \mathrm{Mn}_{23}$ hydrides $(\mathrm{R}=\mathrm{Gd}$, Ho or Er). J. Magn. Magn. Mater. 1980, 21, 128-132. [CrossRef]

64. Pourarian, F.; Boltich, E.B.; Wallace, W.E.; Malik, S.K. Effect of absorbed hydrogen on magnetic ordering in $\mathrm{Tb}_{6} \mathrm{Mn}_{23}$ and $\mathrm{Dy}_{6} \mathrm{Mn}_{23}$. J. Less-Common Met. 1980, 74, 153-159. [CrossRef]

65. Szytuła, A.; Szott, I. Magnetic properties of ternary $\mathrm{RMn}_{2} \mathrm{Si}_{2}$ and $\mathrm{RMn}_{2} \mathrm{Ge}_{2}$ compounds. Solid State Commun. 1981, 40, 199-202. [CrossRef]

66. Hofmann, M.; Campbell, S.J.; Edge, A.V.J. EuMn $\mathrm{Ge}_{2}$ and $\mathrm{EuMn}_{2} \mathrm{Si}_{2}$ : Magnetic structures and valence transitions. Phys. Rev. B 2004, 69, 174432. [CrossRef]

67. Szytuka, A.; Siek, S.; Leciejewicz, J.; Zygmunt, A.; Ban, Z. Neutron diffraction study of $\mathrm{UT}_{2} \mathrm{X}_{2}$ (T: Mn, Fe, X: Si, Ge) intermetallic systems. J. Phys. Chem. Solids 1988, 49, 1113-1118. [CrossRef]

68. Fukamichi, K. Antiferromagnetic Materials; Kyoritsu: Tokyo, Japan, 2014.

69. Liu, Z.H.; Zhang, Y.J.; Liu, G.D.; Ding, B.; Liu, E.K.; Jafri, H.M.; Hou, Z.P.; Wang, W.H.; Ma, X.Q.; Wu, G.H. Transition from Anomalous Hall Effect to Topological Hall Effect in Hexagonal Non-Collinear Magnet $\mathrm{Mn}_{3}$ Ga. Sci. Rep. 2017, 7, 515. [CrossRef] [PubMed]

70. Morales, M.; Artigas, M.; Bacmann, M.; Fruchart, D.; Skolozdra, R.; Soubeyroux, J.L.; Wolfers, P. Comparison of the magnetic properties of $\mathrm{ErMn}_{12-\mathrm{x}} \mathrm{Fe}_{\mathrm{x}}$ series with their related hydrides and carbides. J. Magn. Magn. Mater. 1999, 196, 703-704. [CrossRef] 
71. Stankiewicz, J.; Bartolomé, J.; Fruchart, D. Spin Disorder Scattering in Magnetic Metallic Alloys. Phys. Rev. Lett. 2002, 89, 106602. [CrossRef]

72. Yang, J.B.; Yelon, W.B.; James, W.J.; Cai, S.; Eckert, D.; Handstein, A.; Müller, K.H.; Yang, Y.C. Structural and magnetic properties of $\mathrm{R}\left(\mathrm{Fe}_{\mathrm{x}} \mathrm{Mn}_{1-\mathrm{x}}\right)_{12}(\mathrm{R}=\mathrm{Ho}, \mathrm{Y})$. Phys. Rev. B 2002, 65, 064444. [CrossRef]

73. Piqué, C.; Blanco, J.A.; Burriel, R.; Abad, E.; Artigas, M.; Fernández-Díaz, M.T. Influence of 3d-4f interactions in the magnetic phases of $\mathrm{RFe}_{\mathrm{x}} \mathrm{Mn}_{12-\mathrm{x}}(\mathrm{R}=\mathrm{Gd}, \mathrm{Tb}$, and $\mathrm{Dy})$ compounds: Coexistence of ferromagnetism and antiferromagnetism at different crystallographic sites. Phys. Rev. B 2007, 75, 224424. [CrossRef]

74. Kirchmayr, H. Magnetic properties of rare earth-Manganese compounds. IEEE Trans. Magn. 1966, 2, $493-499$. [CrossRef]

75. Muro, Y.; Nakamura, H.; Kohara, T. Magnetism of $\mathrm{ScMn}_{4} \mathrm{Al}_{8}$. In Proceedings of the Physical Society of Japan Autumn Meeting 2005, Kyotanabe, Japan, 19-22 September 2005.

76. Felner, I.; Nowik, I. Magnetism and hyperfine interactions of ${ }^{57} \mathrm{Fe},{ }^{151} \mathrm{Eu},{ }^{155} \mathrm{Gd},{ }^{161} \mathrm{Dy},{ }^{166} \mathrm{Er}$ and ${ }^{170} \mathrm{Yb}$ in $\mathrm{RM}_{4} \mathrm{Al}_{8}$ compounds $(\mathrm{R}=$ rare earth or $\mathrm{Y}, \mathrm{M}=\mathrm{Cr}, \mathrm{Mn}, \mathrm{Fe}, \mathrm{Cu})$. J. Phys. Chem. Solids 1979, 40, 1035-1044. [CrossRef]

77. Bourée-Vigneron, F.; Pinot, M.; Olès, A.; Baran, A.; Suski, W. UCr ${ }_{4} \mathrm{Al}_{8}$ and $\mathrm{UMn}_{4} \mathrm{Al}_{8}$ : $\mathrm{Neutron}^{\text {diffraction }}$ study. Solid State Commun. 1990, 75, 929-933. [CrossRef]

78. Duong, N.P.; Klaasse, J.C.P.; Brück, E.; de Boer, F.R.; Buschow, K.H.J. Magnetic properties of $\mathrm{GdT}_{4} \mathrm{Al}_{8}$ and $\mathrm{GdT}_{6} \mathrm{Al}_{6}$ compounds $(\mathrm{T}=\mathrm{Cr}, \mathrm{Mn}, \mathrm{Cu})$. J. Alloy. Compd. 2001, 315, 28-35. [CrossRef]

79. Schobinger-Papamantellos, P.; Fischer, P.; de Groot, C.H.; de Boer, F.R.; Buschow, K.H.J. Magnetic properties and neutron diffraction of $\mathrm{TbMn}_{4} \mathrm{Al}_{8}$. J. Alloy. Compd. 1996, 232, 154-159. [CrossRef]

80. Baran, A.; Suski, W.; Mydlarz, T. Magnetic properties of the (U, Th) $(\mathrm{Cr}, \mathrm{Mn})_{4} \mathrm{Al}_{8}$ compounds. J. Magn. Magn. Mater. 1987, 63, 196-198. [CrossRef]

81. Fruchart, R.; Roger, A.; Senateur, J.P. Crystallographic and Magnetic Properties of Solid Solutions of the Phosphides $\mathrm{M}_{2} \mathrm{P}, \mathrm{M}=\mathrm{Cr}, \mathrm{Mn}, \mathrm{Fe}, \mathrm{Co}$, and Ni. J. Appl. Phys. 1969, 40, 1250-1257. [CrossRef]

82. Srivastava, B.K.; Ericsson, T.; Haggstrom, L.; Verma, H.R.; Andersson, Y.; Rundqvist, S. A Mossbauer study of the $\left(\mathrm{Fe}_{1-\mathrm{x}} \mathrm{Mn}_{\mathrm{x}}\right)_{2} \mathrm{P}$ system. J. Phys. C 1987, 20, 463-472. [CrossRef]

83. Suzuki, N.; Asahi, R.; Kishida, Y.; Masuoka, Y.; Sugiyama, J. Measurement and ab initio calculation of the structural parameters and physical properties of $3 \mathrm{~d}$ transition intermetallics TiMP (M = Cr, Mn, Fe, Co, or Ni). Mater. Res. Express 2017, 4, 046505. [CrossRef]

84. Kanomata, T.; Kawashima, T.; Utsugi, H.; Goto, T.; Hasegawa, H.; Kaneko, T. Magnetic properties of the intermetallic compounds $\mathrm{MM}^{\prime} \mathrm{X}\left(\mathrm{M}=\mathrm{Cr}, \mathrm{Mn}, \mathrm{M}^{\prime}=\mathrm{Ru}, \mathrm{Rh}, \mathrm{Pd}\right.$, and $\left.\mathrm{X}=\mathrm{P}, \mathrm{As}\right)$. J. Appl. Phys. 1991, 69, 4639-4641. [CrossRef]

85. Jeitschko, W.; Johnson, V. High pressure $\mathrm{Mn}_{2}$ As with $\mathrm{Fe}_{2} \mathrm{P}$-type structure. Acta Crystallogr. Sect. B 1972, 28, 1971-1973. [CrossRef]

86. Bartolomé, J.; García, J.; Floría, L.M.; Falo, F.; Navarro, R.; Fruchart, D.; Bacmann, M.; de Jongh, L.J. A magnetic Kosterlitz-Thouless transition in quasi 2-d MnRhAs? J. Magn. Magn. Mater. 1986, 54-57, 1547-1548. [CrossRef]

87. Bażela, W. Magnetic properties of intermetallic compounds RhMnGe, PdMnGe, $\mathrm{Pd}_{1.5} \mathrm{Mn}_{0.5} \mathrm{Si}_{1} \mathrm{Pd}_{1.5} \mathrm{Mn}_{0.5} \mathrm{Ge}$ and RhMnSi. J. Less-Common Met. 1984, 100, 341-346. [CrossRef]

88. Bazela, W.; Szytuła, A.; Todorović, J.; Tomkowicz, Z.; Zięba, A. Crystal and magnetic structure of NiMnGe. Phys. Status Solidi A 1976, 38, 721-729. [CrossRef]

89. Brück, E.; van Streepen, T.; Duijn, H.G.M.; Haanappel, E.G.; de Boer, F.R.; Buschow, K.H. J Magnetic and transport properties of $\mathrm{MnPtAl}_{1-\mathrm{x}} \mathrm{Ga}_{\mathrm{x}}$ compounds. J. Magn. Magn. Mater. 1988, 177-181, 767-768. [CrossRef]

90. Buschow, K.H.J.; De Mooij, D.B. Crystal structure and magnetic properties of PtMnGa and PtMnAl. J. Less-Common Met. 1984, 99, 125-130. [CrossRef]

91. Kübler, J. Ab initio estimates of the Curie temperature for magnetic compounds. J. Phys. Condens. Matter 2006, 18, 9795-9808. [CrossRef]

92. Krishnamurthy, V.V.; Kawamura, N.; Suzuki, M.; Ishikawa, T.; Mankey, G.J.; Raj, P.; Sathyamoorthy, A.; Joshi, A.G.; Malik, S.K. Evidence for a magnetic moment on Ir in IrMnAl from x-ray magnetic circular dichroism. Phys. Rev. B 2003, 68, 214413. [CrossRef]

93. Buschow, K.H.J.; van Engen, P.G.; Jongebreur, R. Magneto-optical properties of metallic ferromagnetic materials. J. Magn. Magn. Mater. 1983, 38, 1-22. [CrossRef] 
94. Masumoto, H.; Watanabe, K. New Compounds of the Clb, $\mathrm{Cl}$ Types of RhMnSb, IrMnSn and IrMnAl, New $\mathrm{L} 2_{1}$ (Heusler) Type of $\mathrm{Ir}_{2} \mathrm{MnAl}$ and $\mathrm{Rh}_{2} \mathrm{MnAl}$ Alloys, and Magnetic Properties. J. Phys. Soc. Jpn. 1972, 32, 281. [CrossRef]

95. Chikazumi, S. Physics of Ferromagnetism; Oxford University Press: New York, NY, USA, 1997.

96. Helmholdt, R.B.; Buschow, K.H.J. A neutron diffraction and magnetization study of PdMnTe. J. Less-Common Met. 1986, 123, 169-173. [CrossRef]

97. Offernes, L.; Ravindran, P.; Kjekshus, A. Prediction of large polar Kerr rotation in the Heusler-related alloys AuMnSb and AuMnSn. Appl. Phys. Lett. 2003, 82, 2862-2864. [CrossRef]

98. Beckman, O.; Lundgren, L. Compounds of transition elements with nonmetals. In Handbook of Magnetic Materials; Buschow, K.H.J., Ed.; Elsevier: New York, NY, USA, 1991; Volume 6, pp. 181-287.

99. Lamichhane, T.N.; Taufour, V.; Masters, M.W.; Parker, D.S.; Kaluarachchi, U.S.; Thimmaiah, S.; Bud'ko, S.L.; Canfield, P.C. Discovery of ferromagnetism with large magnetic anisotropy in ZrMnP and HfMnP. Appl. Phys. Lett. 2016, 109, 092402. [CrossRef]

100. Ventutini, G.; ljjaali, I.; Ressouche, E.; Malaman, B. Neutron diffraction study of the HoMnSi, LuMnSi and $\mathrm{Sc}_{0.9} \mathrm{Lu}_{0.1} \mathrm{MnSi}$ compounds. J. Alloy. Compd. 1997, 256, 65-75. [CrossRef]

101. Hoffmann, R.-D.; Pöttgen, R.; Chevalier, B.; Gaudin, E.; Matar, S.F. The ternary germanides UMnGe and $\mathrm{U}_{2} \mathrm{Mn}_{3}$ Ge. Solid State Sci. 2013, 21, 73-80. [CrossRef]

102. Venturini, G.; Malaman, B.; Ressouche, E. Neutron diffraction study of the TbMnGe compound. J. Alloy. Compd. 1996, 243, 98-105. [CrossRef]

103. Klosek, V.; Vernière, A.; Ouladdiaf, B.; Malaman, B. Crystal and magnetic structures of the R(=Y, Dy-Tm)MnGe compounds. J. Magn. Magn. Mater. 2003, 256, 69-92. [CrossRef]

104. Umetsu, R.Y.; Fukamichi, K.; Sakuma, A. Electrical and magnetic properties of antiferromagnetic $\mathrm{L} 1_{0}$-type Mn alloys. Mater. Jpn. 2004, 43, 831-839. [CrossRef]

105. Cui, B.Z.; Marinescu, M.; Liu, J.F. Ferromagnetic Tetragonal L1 $1_{0}$-Type MnGa Isotropic Nanocrystalline Microparticles. IEEE Trans. Magn. 2013, 49, 3322-3325. [CrossRef]

106. Sakuma, A. Electronic Structure and Magnetocrystalline Anisotropy Energy of MnAl. J. Phys. Soc. Jpn. 1994, 63, 1422-1428. [CrossRef]

107. Suits, J.C. New magnetic compounds with Heusler and Heusler-related structures. Phys. Rev. B 1976, 14, 4131-4135. [CrossRef]

108. Umetsu, R.Y.; Mitsui, Y.; Yuito, I.; Takeuchi, T.; Kawarada, H. Substitution Effects of Cr or Fe on the Curie Temperature for Mn-Based Layered Compounds MnAlGe and MnGaGe With $\mathrm{Cu}_{2} \mathrm{Sb}$-Type Structure. IEEE Trans. Magn. 2014, 50,1-4. [CrossRef]

109. Shibata, K.; Shinohara, T.; Watanabe, H. Magnetic Properties of A New Ferromagnetic Compound MnGaGe. J. Phys. Soc. Jpn. 1972, 32, 1431. [CrossRef]

110. Matsuzaki, H.; Endo, S.; Notsu, Y.; Ono, F.; Kanomata, T.; Kaneko, T. Pressure Effect on Curie Temperature in MnZnSb. Jpn. J. Appl. Phys. 1993, 32, 271-272. [CrossRef]

111. Beleanu, A.; Kiss, J.; Kreiner, G.; Köhler, C.; Müchler, L.; Schnelle, W.; Burkhardt, U.; Chadov, S.; Medvediev, S.; Ebke, D.; et al. Large resistivity change and phase transition in the antiferromagnetic semiconductors LiMnAs and LaOMnAs. Phys. Rev. B 2013, 88, 184429. [CrossRef]

112. Kido, H.; Hoshikawa, T.; Shimada, M.; Koizumi, M. Preparation and magnetic properties of YMnSi. Phys. Status Solidi A 1985, 88, K39-K43. [CrossRef]

113. Ovtchenkova, I.A.; Nikitin, S.A.; Ivanova, T.I.; Tskhadadze, G.A.; Chistyakov, O.D.; Badurski, D. Magnetocaloric effect and magnetoresistance in $\mathrm{Gd}_{x} \mathrm{La}_{1-\mathrm{x}} \mathrm{MnSi}$ compounds. J. Magn. Magn. Mater. 2006, 300, e493-e496. [CrossRef]

114. Welter, R.; Venturini, G.; Ressouche, E.; Malaman, B. Magnetic properties of TbMnSi, determined by susceptibility measurements and neutron diffraction study. J. Alloy. Compd. 1994, 210, 273-277. [CrossRef]

115. Welter, R.; Venturini, G.; Ressouche, E.; Malaman, B. Neutron diffraction studies of the CeFeSi-type CaMnSi and CaMnGe compounds. Solid State Commun. 1996, 97, 503-507. [CrossRef]

116. Welter, R.; Venturini, G.; Ressouche, E.; Malaman, B. Crystallographic data and magnetic properties of new CeFeSi-type RMnGe compounds $(\mathrm{R}=\mathrm{La} \mathrm{Sm})$ studied by magnetization and neutron diffraction measurements. J. Alloy. Compd. 1995, 228, 59-74. [CrossRef] 
117. Dascoulidou, A.; Müller, P.; Bronger, W. Ternäre Mangan-Verbindungen AMnX (A ^̂ Mg, Ca, Sr oder $\mathrm{Ba} ; \mathrm{X} \hat{=} \mathrm{Si}$, Ge oder $\mathrm{Sn})$ : Neutronenbeugungsuntersuchungen zur Charakterisierung der magnetischen Eigenschaften. Z. Anorg. Allg. Chem. 1998, 624, 124-128. [CrossRef]

118. Roger, J.; Yahia, M.B.; Babizhetskyy, V.; Bauer, J.; Cordier, S.; Guérin, R.; Hiebl, K.; Rocquefelte, X.; Saillard, J.-Y.; Halet, J.-F. $\mathrm{Mn}_{5} \mathrm{Si}_{3}$-type host-interstitial boron rare-earth metal silicide compounds $\mathrm{RE}_{5} \mathrm{Si}_{3}$ : Crystal structures, physical properties and theoretical considerations. J. Solid State Chem. 2006, 179, 2310-2328. [CrossRef]

119. Mahon, T.; Gaudin, E.; Villesuzanne, A.; Chevalier, B.; Tencé, S. Effect of Carbon Insertion on the Structural and Magnetic Properties of NdScSi. Inorg. Chem. 2019, 58, 15255-15268. [CrossRef]

120. Coey, J.M.D. New permanent magnets; manganese compounds. J. Phys. Condens. Matter 2014, $26,064211$. [CrossRef] [PubMed]

121. Tanaka, S.; Terada, H.; Shirakawa, N.; Tsubota, M.; Kitagawa, J. The Impact of the Composition Effect on Ferromagnetic Properties of $\mathrm{Tb}_{2} \mathrm{Co}_{2} \mathrm{Ga}$. Metals 2019, 9, 1242. [CrossRef]

122. Kitagawa, J.; Takeda, N.; Sakai, F.; Ishikawa, M. Effect of composition in $(R E)_{3} P_{20} \mathrm{Ge}_{6}(\mathrm{RE}=\mathrm{La}, \mathrm{Ce}$ and $\mathrm{Nd})$. J. Phys. Soc. Jpn. 1999, 68, 3413-3416. [CrossRef]

123. Kitagawa, J.; Terada, H.; Shirakawa, N.; Tsubota, M.; Nose, A.; Tanaka, S. Composition effect in ferromagnetic properties of $\mathrm{Tb}_{3} \mathrm{Co}_{3} \mathrm{Ga}$. Results Phys. 2019, 15, 102591. [CrossRef]

124. Lu, Q.M.; Yue, M.; Zhang, H.G.; Wang, M.L.; Yu, F.; Huang, Q.Z.; Ryan, D.H.; Altounian, Z. Intrinsic magnetic properties of single-phase $\mathrm{Mn}_{1+\mathrm{x}} \mathrm{Ga}(0<\mathrm{x}<1)$ alloys. Sci. Rep. 2015, 5, 17086.

125. Enkovaara, J.; Heczko, O.; Ayuela, A.; Nieminen, R.M. Coexistence of ferromagnetic and antiferromagnetic order in Mn-doped $\mathrm{Ni}_{2} \mathrm{MnGa}$. Phys. Rev. B 2003, 67, 212405. [CrossRef]

126. Larson, P.; Mazin, I.I.; Papaconstantopoulos, D.A. Effects of doping on the magnetic anisotropy energy in $\mathrm{SmCO}_{5-\mathrm{x}} \mathrm{Fe}_{\mathrm{x}}$ and $\mathrm{YCo}_{5-\mathrm{x}} \mathrm{Fe}_{\mathrm{x}}$. Phys. Rev. B 2004, 69, 134408. [CrossRef]

127. Sakuma, A.; Manabe, Y.; Kota, Y. First principles calculation of magnetocrystalline anisotropy energy of MnBi and $\mathrm{MnBi}_{1-\mathrm{x}} \mathrm{Sn}_{\mathrm{x}}$. J. Phys. Soc. Jpn. 2013, 82, 073704. [CrossRef]

128. Pandey, T.; Parker, D.S. Magnetic properties and magnetocrystalline anisotropy of $\mathrm{Nd}_{2} \mathrm{Fe}_{17}, \mathrm{Nd}_{2} \mathrm{Fe}_{17} \mathrm{X}_{3}$, and related compounds. Sci. Rep. 2018, 8, 3601. [CrossRef]

129. Miyahara, J.; Shirakawa, N.; Setoguchi, Y.; Tsubota, M.; Kuroiwa, K.; Kitagawa, J. Hill plot focusing on Ce compounds with high magnetic ordering temperatures and consequent study of $\mathrm{Ce}_{2} \mathrm{AuP}_{3}$. J. Supercond. Nov. Magn. 2018, 31, 3559-3564. [CrossRef]

130. Yamada, Y.; Ueno, K.; Fukumura, T.; Yuan, H.T.; Shimotani, H.; Iwasa, Y.; Gu, L.; Tsukimoto, S.; Ikuhara, Y.; Kawasaki, M. Electrically Induced Ferromagnetism at Room Temperature in Cobalt-Doped Titanium Dioxide. Science 2011, 332, 1065-1067. [CrossRef] [PubMed]

131. Kitagawa, J.; Kitajima, D.; Shimokawa, K.; Takaki, H. Photoinduced Kondo effect in $\mathrm{CeZn}_{3} \mathrm{P}_{3}$. Phys. Rev. B 2016, 93, 035122. [CrossRef]

132. Stewart, G.R. Non-Fermi-liquid behavior in $d$ - and $f$-electron metals. Rev. Mod. Phys. 2001, 73, 797-855. [CrossRef]

133. Eom, D.; Ishikawa, M.; Kitagawa, J.; Takeda, N. Suppression of Antiferromagnetism by Kondo Effect and Quantum Critical Behavior in CeCoGe ${ }_{3-\mathrm{x}} \mathrm{Si}_{\mathrm{x}}(0 \leq \mathrm{x} \leq 3)$. J. Phys. Soc. Jpn. 1998, 67, 2495-2500. [CrossRef]

134. Custers, J.; Gegenwart, P.; Wilhelm, H.; Neumaier, K.; Tokiwa, Y.; Trovarelli, O.; Geibel, C.; Steglich, F.; Pépin, C.; Coleman, P. The break-up of heavy electrons at a quantum critical point. Nature 2003, 424, 524-527. [CrossRef]

135. Löhneysen, H.V.; Rosch, A.; Vojta, M.; Wölfle, P. Fermi-liquid instabilities at magnetic quantum phase transitions. Rev. Mod. Phys. 2007, 79, 1015-1075. [CrossRef]

136. Huang, C.-L.; Hallas, A.M.; Grube, K.; Kuntz, S.; Spieß, B.; Bayliff, K.; Besara, T.; Siegrist, T.; Cai, Y.; Beare, J.; et al. Quantum Critical Point in the Itinerant Ferromagnet $\mathrm{Ni}_{1-x} \mathrm{Rh}_{\mathrm{x}}$. Phys. Rev. Lett. 2020, 124, 117203. [CrossRef]

137. Akayama, M.; Fujii, H.; Yamamoto, K.; Tatami, K. Physical properties of nitrogenated $\mathrm{RFe}_{11} \mathrm{Ti}$ intermetallic compounds $(\mathrm{R}=\mathrm{Ce}$, Pr and Nd) with ThMn 12 -type structure. J. Magn. Magn. Mater. 1994, 130, 99-107. [CrossRef]

Publisher's Note: MDPI stays neutral with regard to jurisdictional claims in published maps and institutional affiliations. 